\title{
EFFECT OF FE (III) AND CHELATING AGENTS ON \\ PERFORMANCE OF NEW VES-BASED ACID SOLUTION IN \\ HIGH-TEMPERATURE WELLS
}

\author{
A Thesis \\ by \\ FATEMEH SADAT ZEBARJAD
Submitted to the Office of Graduate and Professional Studies of Texas A\&M University
in partial fulfillment of the requirements for the degree of
MASTER OF SCIENCE

$\begin{array}{ll}\text { Chair of Committee, } & \text { Hisham A. Nasr-El-Din } \\ \text { Committee Members, } & \begin{array}{l}\text { Jerome J. Schubert } \\ \text { Mahmoud El-Halwagi }\end{array} \\ \text { Head of Department, } & \text { A. Daniel Hill }\end{array}$

May 2017

Major Subject: Petroleum Engineering

Copyright 2017 Fatemeh Sadat Zebarjad 


\begin{abstract}
Viscoelastic surfactant (VES)-based acid systems are used in acid-diversion applications. However, high-temperature, interaction of the VES and Fe(III) (as a contaminant), addition of alcohol-based additives, and chelating agents all interfere with the apparent viscosity of the VES-based acid and reduce its effectiveness. This research introduces a new VES-based acid system that can be used for diversion in hightemperature formation matrix acidizing. This VES-based acid system exhibits high thermal stability in the presence of $\mathrm{Fe}(\mathrm{III})$ contamination and chelating agents. Also, this work elucidates the reaction mechanisms between VES, Fe(III), and two chelating agents (hydroxyethylethylenediaminetriacetic acid (HEDTA), and Glutamic acid diacetic acid (GLDA)) in spent acids.

To study the rheological properties of the VES-based acid, three different formulations of spent acid (20 wt\% hydrochloric acid ( $\mathrm{HCl}), 5 \mathrm{vol} \% \mathrm{VES})$ were examined. By comparing the apparent viscosity of the three samples as a function of temperature, the same trend (similar viscosity at same temperatures) was illustrated. Moreover, the effect of chelating agents and Fe(III) on VES viscosity in spent acids was investigated. To understand the VES interaction with $\mathrm{Fe}(\mathrm{III})$ in spent conditions, a compatibility test was conducted on the live VES-acid and Fe(III) system. The results showed that the maximum concentration of the Fe(III), which is compatible with live VES-based acid, is 5,000 ppm; however, at higher $\mathrm{Fe}(\mathrm{III})$ concentrations, the VES interacted with the $\mathrm{Fe}(\mathrm{III})$ and precipitated.
\end{abstract}


Rheological measurements were conducted on the spent VES based system with different $\mathrm{Fe}(\mathrm{III})$ concentrations as a function of temperature $\left(80-400^{\circ} \mathrm{F}\right)$ at $\mathrm{pH}$ in the range of 4-5. At Fe(III) concentrations lower than 6,000 ppm, the apparent viscosity of the VESbased solutions increased in temperatures below $150^{\circ} \mathrm{F}$ as the $\mathrm{Fe}(\mathrm{III})$ concentration was increased. At higher temperatures $\left(150-400^{\circ} \mathrm{F}\right)$, the maximum viscosities reduced with iron concentration, but generally they exhibited excellent thermal stability $(150 \mathrm{cp}$ at $\left.400^{\circ} \mathrm{F}\right)$. The spent VES-based solution, when combined with 6,000 ppm Fe(III), entirely loses its viscosity.

Experimental results indicated that the first peak of apparent viscosity of the VESbased solution increases at low concentrations $(0.010 \mathrm{~mol} / \mathrm{L})$ of the chelating agents, HEDTA and GLDA, but for both chelating agents at higher concentrations $(0.053$ and $0.107 \mathrm{~mol} / \mathrm{L})$, the apparent viscosity reduces. Inclusively, the apparent viscosity remained above $140 \mathrm{cp}$ with the highest concentration of chelating agents in the temperature range of $80-400^{\circ} \mathrm{F}$. Furthermore, both chelating agents were added $(1: 1$ molar to $\mathrm{Fe}(\mathrm{III}))$ to VES-based acid solutions with Fe(III) concentrations of 5,000 and 6,000 ppm. The results demonstrated that the negative impact of the chelating agents on the apparent viscosity does not superimpose on the negative effect of $\mathrm{Fe}(\mathrm{III})$. Chelating agents rebuilt the viscosity of the VES-based solution with 6,000 ppm Fe(III). For the 5,000 ppm Fe(III) solution, they reduced the apparent viscosity at lower temperatures $\left(150^{\circ} \mathrm{F}\right)$ and increased the maximum apparent viscosity over a temperature range of $150-250^{\circ} \mathrm{F}$. This work will help to overcome the VES challenging interaction with Fe(III). 


\section{DEDICATION}

This thesis is dedicating to my beloved family especially Seyed Mohammad Zebarjad for his encouragement and also my husband Sadegh for all his support.

Finally, this thesis is dedicated to Dr. Nasr-El- Din who helped me in finishing this journey. 


\section{ACKNOWLEDGEMENTS}

I would like to thank my adviser, Professor Hisham A. Nasr-El-Din, and my committee members, Professor Jerome J. Shubert and Professor Mahmoud El-Halwagi, for their guidance and support throughout the course of this research.

Thanks also go to my friends and colleagues for making my time at Texas A\&M University a great experience. 


\section{CONTRIBUTORS AND FUNDING SOURCES}

\section{Contributors}

This work was supported by Professor Hisham A. Nasr-El-Din from the Department of Petroleum Engineering, Texas A\&M University. Also, it should be noted that I completed all the works for this dissertation independently.

\section{Funding Sources}

This Graduate study was supported by Professor Hisham A. Nasr-El-Din from Texas A\&M University and also Well Services Group. 


\section{NOMENCLATURE}

$\mathrm{a}_{0}$

CDTA

CMC

DOTA

DTPA

EDTA

GLDA

HEDTA

HEIDA

ICA

$1_{\mathrm{c}}$

$\mathrm{t}$

$\mathrm{V}_{0}$

VES
Optimal head group area

trans-1,3-cyclohexylenediaminetetraacetic acid

Critical micelle concentration

1,4,7,10-tetraazacyclododecane-1,4,7,10-tetraacetic acid

Diethylene triamine pentaacetic acid

Ethyene diamine tetraacetic acid

Glutamic acid diacetic acid

Hydroxyethylethylenediaminetriacetic acid

Hydroxyl Iminodiaceticacid

Iron Control Agent

Critical chain length

Times, minutes

Volume of the hydrocarbon chain or chains

Viscoelastic surfactant

vii 


\section{TABLE OF CONTENTS}

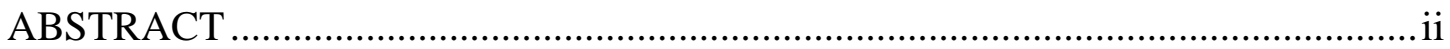

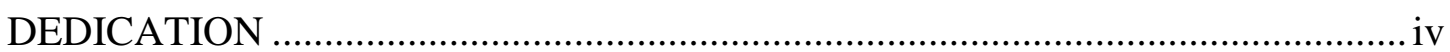

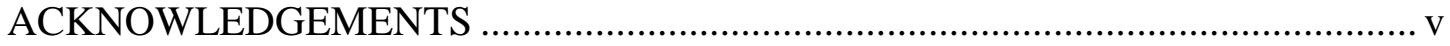

CONTRIBUTORS AND FUNDING SOURCES .................................................. vi

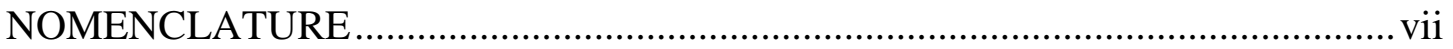

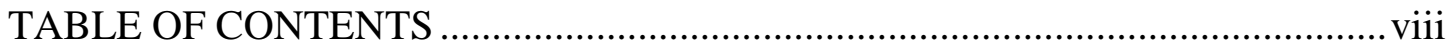

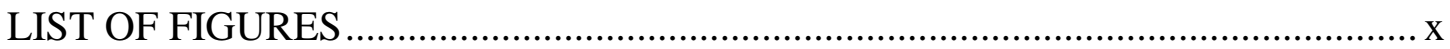

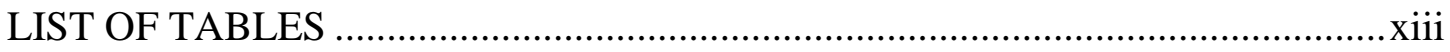

CHAPTER I INTRODUCTION AND LITERATURE REVIEW ............................ 1

1.1. Carbonate matrix acidizing .................................................................. 1

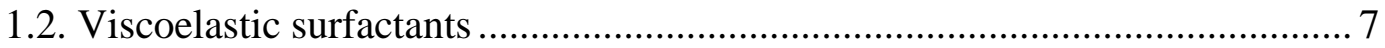

1.3. Impact of $\mathrm{Fe}(\mathrm{III})$ on the viscoelastic surfactant-based acids ....................... 13

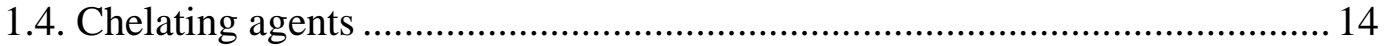

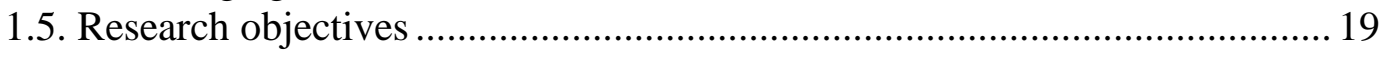

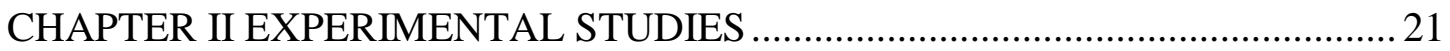

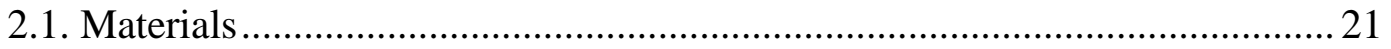

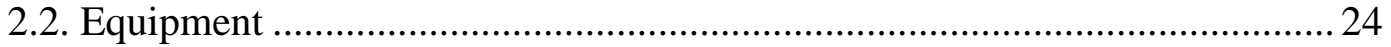

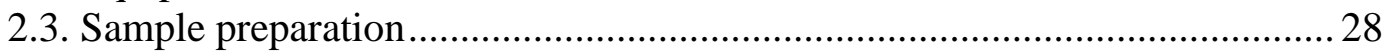

CHAPTER III EFFECT OF DIFFERENT PREPARATION METHODS OF SPENT ACID ON THE APPARENT VISCOSITY OF THE VES-

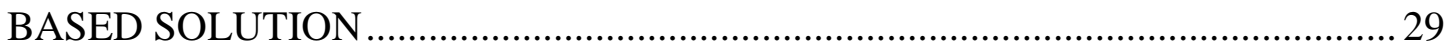

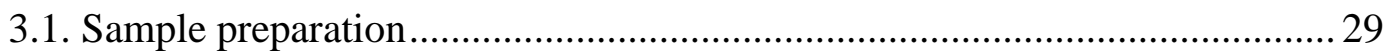

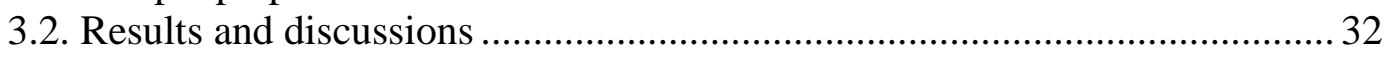

CHAPTER IV EFFECT OF DIFFERENT CONCENTRATIONS OF FE (III) ON THE LIVE AND SPENT VES-BASED SOLUTIONS 


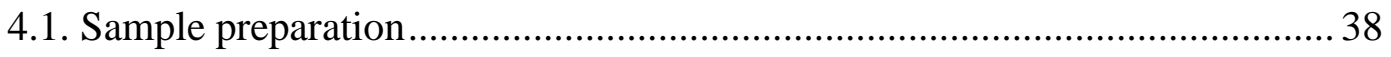

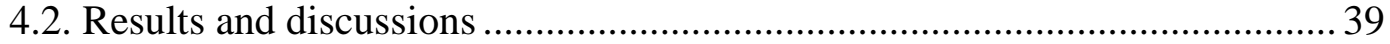

CHAPTER V EFFECT OF DIFFERENT CHELATING AGENTS ON THE APPARENT VISCOSITY OF THE SPENT VES-BASED ACID .......................... 44

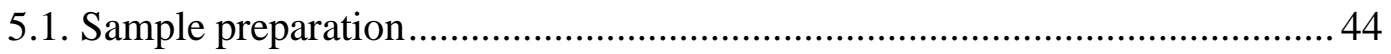

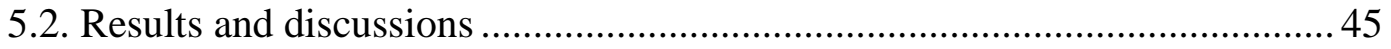

CHAPTER VI EFFECT OF CHELATING AGENT ADDITION TO

THE SPENT VES-BASED ACID SOLUTION WITH DIFFERENT CONCENTRATIONS OF IRON (III) ON THE APPARENT VISCOSITY

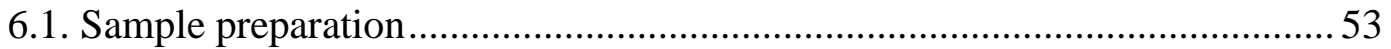

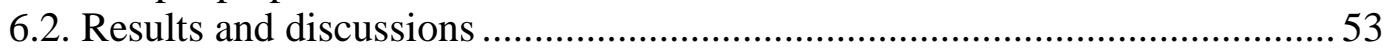

CHAPTER VII CONCLUSIONS AND RECOMMENDATIONS .......................... 58

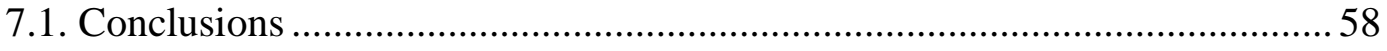

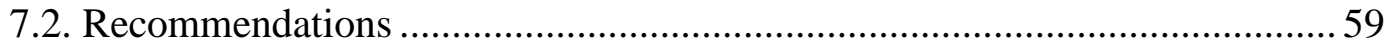

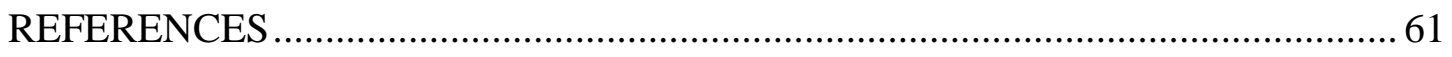

APPENDIX A DETAILS OF EXPERIMENTAL METHOD ................................. 67 


\section{LIST OF FIGURES}

Page

Fig. 1. 1. The structure of partially hydrolyzed polyacrylamide.

Fig. 1.2. Fe(III) and polymer precipitation in the core after acidizing treatment (Lynn and Nasr-El-Din 2001).

Fig. 1.3. Core surface before and after polymer injection (Nasr-El-Din et al. 2002). 5

Fig. 1. 4. Acidizing heterogeneous carbonate reservoir without diverting agent......... 6

Fig. 1. 5. Acidizing heterogeneous carbonate reservoir with diverting agent.............. 7

Fig. 1. 6. Schematic diagram of surface-active molecule (Malik et al. 2011). ............ 9

Fig. 1. 7. Micellization process (Hull et al. 2015)................................................ 11

Fig. 1.8. Schematics of the micelles based on molecular packing parameter (Hull et al. 2015).

Fig. 1.9. Aminocarboxylic acids chemical structure. 16

Fig. 2. 1. Molecular structure of the VES. 22

Fig. 2.2. Molecular structures of GLDA-Na4 (left) and HEDTA-Na (right). (LePage et al. 2011).

Fig. 2.3. Oaktan pH 510 meter. 25

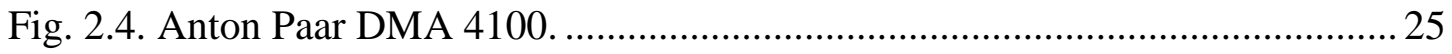

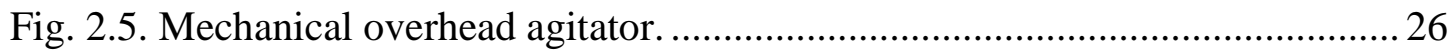

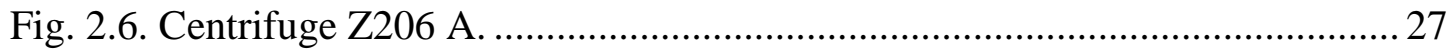

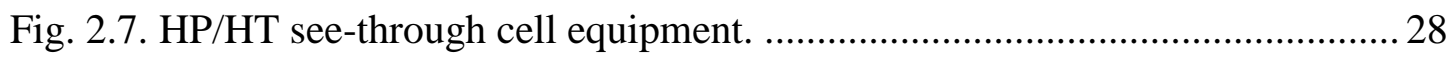

Fig. 3.1. Solution mixture in the mechanical agitator. ........................................ 30

Fig. 3.2. Thermal stability of 5 vol\% VES, 2 vol\% corrosion inhibitor, and $20 \mathrm{wt} \% \mathrm{HCl}$ at $200^{\circ} \mathrm{F}$ and 400 psi for 6 hours. 
Fig. 3.3. Viscosity versus shear rate of the VES solution (5 vol\% VES, 2 vol\% corrosion inhibitor, and $20 \mathrm{wt} \% \mathrm{HCl}$ ) at $77^{\circ} \mathrm{F}$ and 300 psi before and after heating.

Fig. 3.4. Effect of the three different methods of spent VES solution preparation (spent $20 \mathrm{wt} \% \mathrm{HCl}$ and $5 \mathrm{vol} \% \mathrm{VES}$ ) on their apparent viscosities at $350 \mathrm{psi}$ and a shear rate of $100 \mathrm{~s}^{-1}$.

Fig. 4.1. 5 vol\% VES solution with $20 \mathrm{wt} \% \mathrm{HCl}$ with different $\mathrm{Fe}$ (III) concentrations $(1,000-10,000 \mathrm{ppm})$ at $75^{\circ} \mathrm{F}$. When iron (III) concentration was greater than 6,000 , a brown precipitate was observed.

Fig. 4.2. 5 vol\% VES solution with $15 \mathrm{wt} \% \mathrm{HCl}$ with $\mathrm{Fe}(\mathrm{III})$ concentrations $(1,000-10,000 \mathrm{ppm})$ at $75^{\circ} \mathrm{F}$. 41

Fig. 4.3. Effect of Fe(III) concentrations on the apparent viscosity of spent 20 wt $\% \mathrm{HCl}$ and $5 \mathrm{vol} \%$ viscoelastic surfactant at $350 \mathrm{psi}$ and a shear rate of $100 \mathrm{~s}^{-1}$.

Fig. 5.1. Thermal stability of 5 vol\% VES, 2 vol\% corrosion inhibitor, and $0.107 \mathrm{~mol} / \mathrm{L} \mathrm{GLDA}$, and $20 \mathrm{wt} \% \mathrm{HCl}$ at $200^{\circ} \mathrm{F}$ and $400 \mathrm{psi}$ for 6 hours. 46

Fig. 5.2. Thermal stability of 5 vol\% VES, 2 vol\% corrosion inhibitor, and $0.107 \mathrm{~mol} / \mathrm{L}$ HEDTA, and $20 \mathrm{wt} \% \mathrm{HCl}$ at $200^{\circ} \mathrm{F}$ and $400 \mathrm{psi}$ for 6 hours.

Fig. 5.3. Viscosity versus shear rate of the VES solution (5 vol\% VES, 2 vol\% corrosion inhibitor, $0.107 \mathrm{~mol} / \mathrm{L}$ GLDA and $20 \mathrm{wt} \% \mathrm{HCl}$ ) at $77^{\circ} \mathrm{F}$ and 300 psi before and after heating. 48

Fig. 5.4. Viscosity versus shear rate of the VES solution (5 vol\% VES, 2 vol\% corrosion inhibitor, $0.107 \mathrm{~mol} / \mathrm{L}$ HEDTA, and $20 \mathrm{wt} \% \mathrm{HCl}$ ) at $77^{\circ} \mathrm{F}$ and 300 psi before and after heating.

Fig. 5.5. Effect of HEDTA concentration on the apparent viscosity of the spent $20 \mathrm{wt} \% \mathrm{HCl}$ and 5 vol\% VES at $350 \mathrm{psi}$ and a shear rate of $100 \mathrm{~s}^{-1}$ 51

Fig. 5.6. Effect of GLDA concentration on the apparent viscosity of the spent $20 \mathrm{wt} \% \mathrm{HCl}$ and $5 \mathrm{vol} \% \mathrm{VES}$ at $350 \mathrm{psi}$ and a shear rate of $100 \mathrm{~s}^{-1}$.

Fig. 6.1. Effect of HEDTA (1:1 molar to Fe(III)) on the apparent viscosity of the spent $20 \mathrm{wt} \% \mathrm{HCl}$ and $5 \mathrm{vol} \% \mathrm{VES}$ with 6,000 ppm Fe(III) at $350 \mathrm{psi}$ and a shear rate of $100 \mathrm{~s}^{-1}$. 
Fig. 6.2. Effect of GLDA (1:1 molar to Fe(III)) on the apparent viscosity of the spent $20 \mathrm{wt} \% \mathrm{HCl}$ and 5 vol\% VES with $6,000 \mathrm{ppm}$ Fe(III) at $350 \mathrm{psi}$ and a shear rate of $100 \mathrm{~s}^{-1}$....

Fig. 6.3. Effect of GLDA and HEDTA (1:1 molar ratio to Fe(III)) on the apparent viscosity of the spent $20 \mathrm{wt} \% \mathrm{HCl}$ VES with $5,000 \mathrm{ppm}$ $\mathrm{Fe}$ (III) at 350 psi and a shear rate of $100 \mathrm{~s}^{-1}$

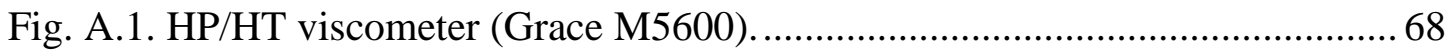

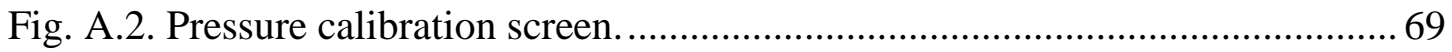

Fig. A.3. Torque calibration screen.......................................................................... 70

Fig. A.4. Single step real time oscillatory................................................................ 71

Fig. A.5. Pre-saved sequence real time oscillatory test screen..................................... 72

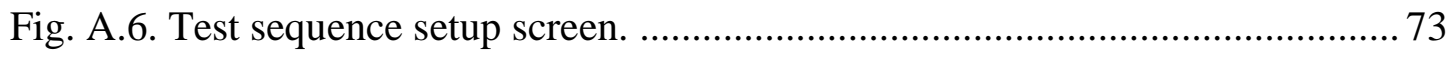

Fig. A.7. Real time test screen............................................................................... 74 


\section{LIST OF TABLES}

Page

Table 1.1. Examples of surfactant applications in the petroleum industry (Schramm et al. 2003).

Table 1. 2. Different types of surfactant (Schramm et al. 2003)............................. 10

Table 2. 1. Properties of the chelating agents, as received at $20^{\circ} \mathrm{C}$........................... 23

Table 2. 2. Corrosion Inhibitor A-5300 composition.............................................. 24 


\section{CHAPTER I}

\section{INTRODUCTION AND LITERATURE REVIEW}

\subsection{Carbonate matrix acidizing}

In matrix acidizing operation, $\mathrm{HCl}$ is injected at a pressure less than the fracturing pressure of the formation to dissolve part of the rock in the target zone and bypass the damage and increase the permeability of the rock. By dissolving the materials plugging the pore spaces or creating new pathways (wormholes), a successful treatment of matrix acidizing will reduce skin factor and thus improve well productivity.

In carbonate acidizing $\mathrm{HCl}$ is the most common acid used, since the $\mathrm{HCl}$ salt created after dissolving the carbonate rock is $\mathrm{NaCl}$ salt which is soluble in water, but the organic acid such as formic and acetic acid will form insoluble salts after reacting with the carbonate formation. Carbonate rocks are originally formed by calcite $\left(\mathrm{CaCO}_{3}\right)$ or dolomite $\left(\mathrm{CaMg}\left(\mathrm{CO}_{3}\right)_{2}\right)$. When stimulating a carbonate reservoir, carbonate rocks, comprising predominantly limestone and dolomite, rapidly dissolve in $\mathrm{HCl}$ by the following reactions (Eqs. 1 and 2):

$\mathrm{CaCO}_{3}+2 \mathrm{HCl} \rightarrow \mathrm{CaCl}_{2}+\mathrm{CO}_{2}+\mathrm{H}_{2} \mathrm{O}$

$\mathrm{CaMg}\left(\mathrm{CO}_{3}\right)_{2}+4 \mathrm{HCl} \rightarrow \mathrm{CaCl}_{2}+\mathrm{MgCl}_{2}+2 \mathrm{CO}_{2}+2 \mathrm{H}_{2} \mathrm{O}$

Over the years companies came up with various additives to the $\mathrm{HCl}$ to enhance the effectiveness of their acidizing treatments. Such additives include surfactants, $\mathrm{pH}$ buffers, corrosion inhibitors, corrosion inhibitor intensifier, friction reducers, etc.. 


\subsubsection{Diversion}

Most of the $\mathrm{HCl}$ is used in higher-permeability zones and less is diverted to the lower-permeability zones. This uneven distribution of the $\mathrm{HCl}$ could cause a major economic loss. Under these circumstances acid diversion is applied to enhance the efficiency of the acidizing process (Chang et al. 2001; Kalfayan and Martin 2009). There are both chemical and mechanical means for acid diversion, but the mechanical methods are limited to openhole, slotted liner and gravel packed completions (Thomas et al. 1998). The goal of the chemical diversion is to viscosify the acid.

In practice, diverting agents and acid could be pumped in alternating stages or continuously. The number of stages depends on the length of zone being treated. Polymer and viscoelastic surfactants are the most common additives that have been developed to be used in acid-diversion applications.

\subsubsection{Polymer-based acid}

Polymers are high molecular weight structures from similar units bonded together. The most common type of polymer used in the industry is partially hydrolyzed polyacrylamide (Fig. 1.1). Yeager et.al (1997) discussed the crosslinked-acid systems of polymer while they maintain higher viscosity compared to their uncrosslinked types in acid (Yeager and Shuchart 1997). Crosslinked-acids consist of two types. The first type is crosslinked before the injection and remains crosslinked during the treatment (Johnson et al. 1988). The second type is uncrosslinked at injection time, but it crosslinks in the 
formation (Yeager and Shuchart 1997; Saxon et al. 2000). The second type is more commonly used in the industry and it is called in-situ-gelled acid.

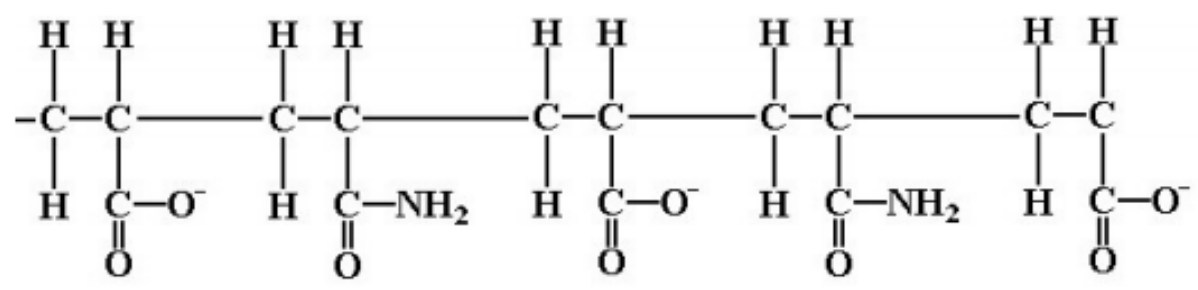

Fig. 1. 1. The structure of partially hydrolyzed polyacrylamide.

The in-situ gelled acids consist of a polymer, a crosslinker (Fe(III), $\mathrm{Zr}(\mathrm{IV})$ ), a breaker, a buffer and other additives. The crosslinking mechanism in in-situ gelled acids is controlled by $\mathrm{pH}$ (Taylor and Nasr-El-Din 2003). The $\mathrm{pH}$ is zero when the polymerbased solution is injected into the formation and it increases as the acid solution reacts with the carbonate reservoir. The crosslinking starts when the $\mathrm{pH}$ approximately reaches 2. The breaker starts to break the polymer when the $\mathrm{pH}$ is greater than 4 to avoid the formation damage.

The outcome of in-situ gelled acids was generally positive. However, there are several concerns related to this system. Loss of permeability because of polymer retention in tight carbonate cores (Taylor and Nasr-El-Din 2003, 2002); precipitation of the Fe(III) crosslinker in sour environments and tight carbonate cores at high temperature (Nasr-ElDin et al. 2002; Lynn and Nasr-El-Din 2001) (Fig 1.2 and 1.3); and consumption of 
hydrogen sulfide $\left(\mathrm{H}_{2} \mathrm{~S}\right)$ scavengers by reacting with the polymer (Nasr-El-Din and AlHumaidan 2001).

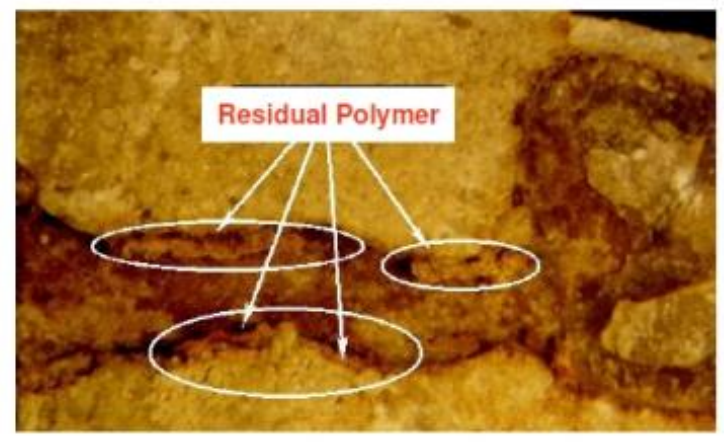

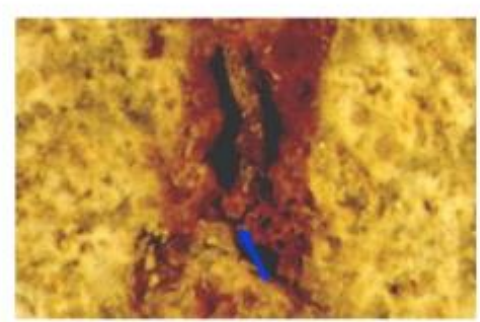

Precipitation in wormhole

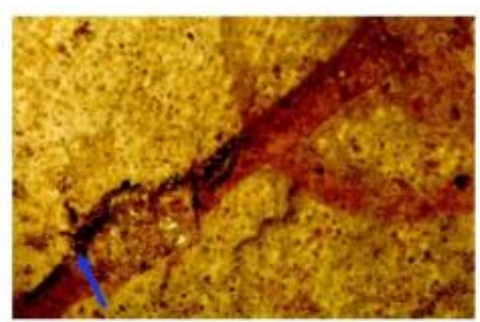

Polymer trapped in the wormhole

Fig. 1.2. $\mathrm{Fe}(\mathrm{III})$ and polymer precipitation in the core after acidizing treatment (Lynn and Nasr-El-Din 2001). 


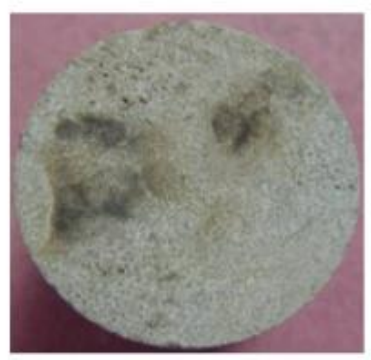

inlet before

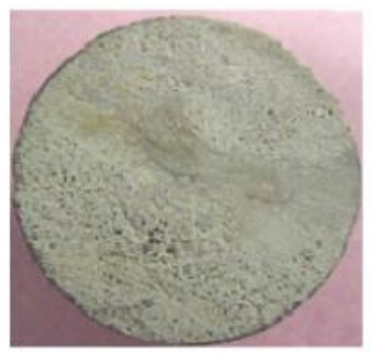

outlet before

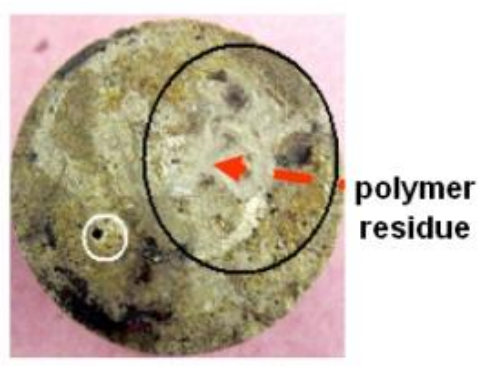

inlet after

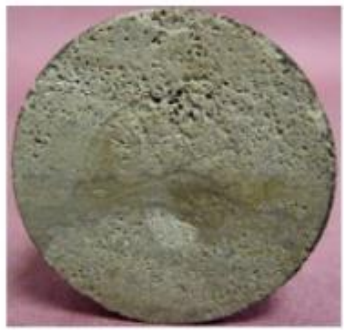

outlet after

Fig. 1.3. Core surface before and after polymer injection (Nasr-El-Din et al. 2002).

\subsubsection{Surfactant-based acid}

Viscoelastic surfactants were introduced to the industry to overcome the problem of polymers (Fu and Chang 2005; Cawiezel and Dawson 2007). Surfactant-based acids do not need metallic crosslinker. They typically consist of hydrochloric acid $(\mathrm{HCl})$, a viscoelastic surfactant, and other additives. These systems were used successfully in matrix stimulation and also in field applications (Al-Mutawa et al. 2005; Nasr-El-Din et al. 2006a; Samuel et al. 2003; Nasr-El-Din and Samuel 2007). Matrix acidizing in carbonate reservoir with different heterogeneity will cause acid to only move forward the higher permeability zones as you can see in Fig. 1.4. To avoid this phenomena, the viscoelastic surfactant in acid solution will increase the viscosity after the reaction of $\mathrm{HCl}$ and carbonate reservoir. The final product of their reaction, $\mathrm{Mg}^{2+}$ and $\mathrm{Ca}^{2+}$ ions, will 
interact with the viscoelastic surfactant and turn their structure to a more viscous form (worm-like). This high viscous solution will block the high permeability zones and allows the acid to stimulate the low permeability zones (Fig. 1.5). The gelled acid could be broken down by converting the surfactant worm-like micelles to spherical micelles, which can be accomplished by reducing the concentration of salts and/or surfactant by the injection water in water or by mixing the spent acid with the oil in oil and gas wells. External and internal breakers (mutual solvent) have also been used to break the worm-like micelle successfully (Nelson et al. 2005; Crews and Huang 2007).

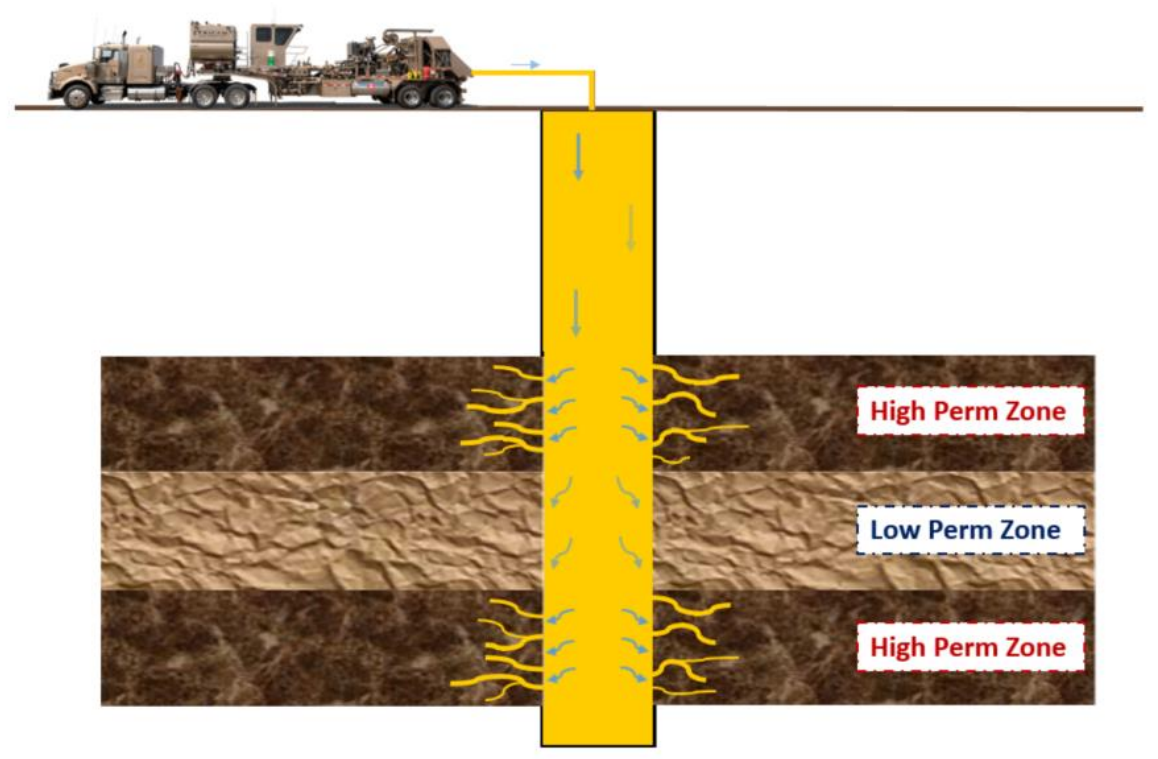

Fig. 1. 4. Acidizing heterogeneous carbonate reservoir without diverting agent. 


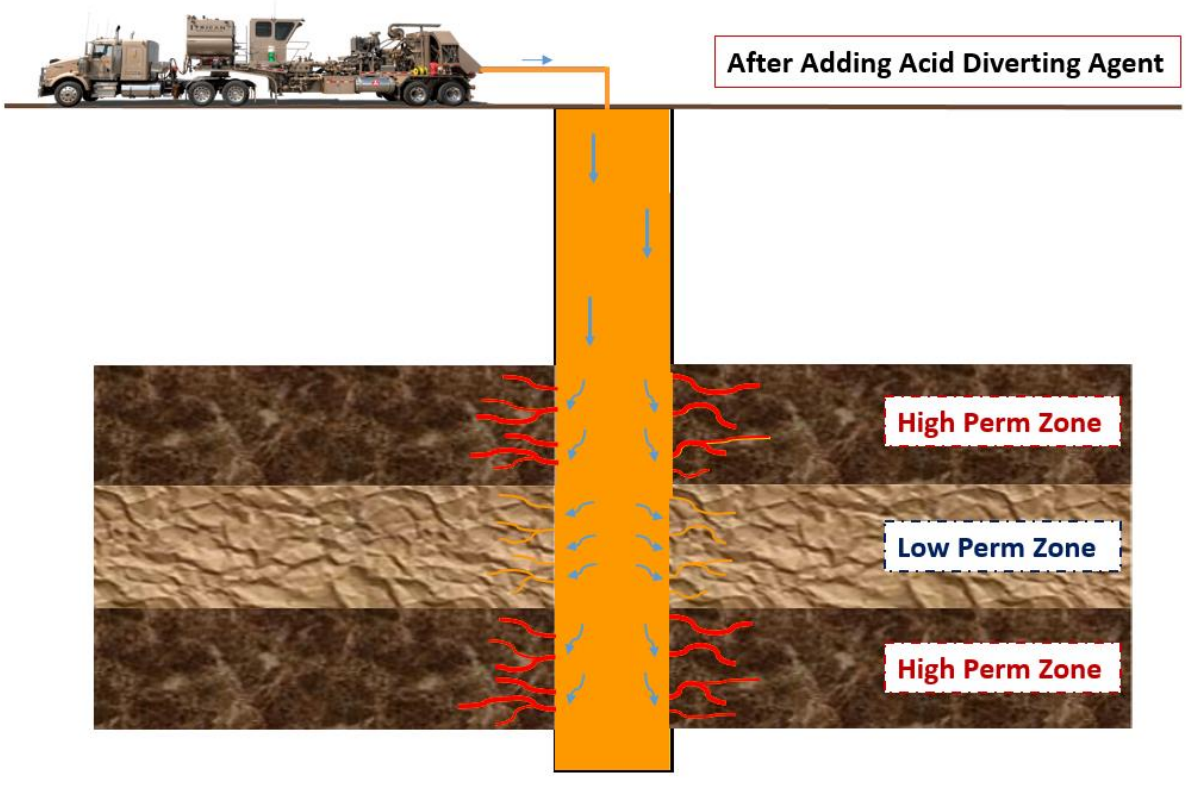

Fig. 1. 5. Acidizing heterogeneous carbonate reservoir with diverting agent.

\subsection{Viscoelastic surfactants}

The chemistry of VES-based fluids is provided in the following sections. The discussion begins with a description of surfactant types. Furthermore, a description of the micellization process is provided, along with the potential sizes and shapes that these structures can form in aqueous fluid. This is important because only certain geometries lead to an enhancement of the solution viscosity.

\subsubsection{Definition and classification of surfactants}

Surfactants are surface active agents that have been used in a wide variety of industrial products, including cleaning detergents, textiles, cosmetics, paper production, 
food, and mining, as well as fluids for the oil and gas industry, which are mentioned in

\section{Table 1.1.}

Table 1.1. Examples of surfactant applications in the petroleum industry (Schramm et al. 2003).

\begin{tabular}{ll}
\hline Gas/liquid systems & Producing oil well and well-head foams \\
& Oil flotation process froth \\
& Distillation and fractionation tower foams \\
& Fuel oil and jet fuel tank (truck) foams \\
& Foam drilling fluid \\
& Foam fracturing fluid \\
& Foam acidizing fluid \\
& Blocking and diverting foams \\
& Gas-mobility control foams \\
& Emulsion drilling fluids \\
Enhanced oil recovery in situ emulsions & Oil sand flotation process slurry \\
Liquid/liquid systems & Oil sand flotation process froths \\
& Well-head emulsion \\
& Heavy oil pipeline emulsion \\
& Fuel oil emulsion \\
& Oil spill emulsions \\
& Tanker bilge emulsions \\
& Reservoir wettability modifiers \\
Reservoir fines stabilizers \\
Tank/vessel sludge dispersants \\
Drilling mud dispersants
\end{tabular}


Surfactants are amphiphilic organic molecules that possess hydrophilic and hydrophobic regions (Karger et al. 1976; Renouf et al. 1998). They have a long hydrocarbon tail and an ionic or polar head group. The surfactant molecules form an interface between two immiscible liquids and larger quantities of surfactant lead to more interfacial area between of the two liquids until eventually they are considered mixed. The specific chemical identity of the polar corresponding lowering of interfacial tension. A schematic diagram of a surfactant is shown in Fig. 1.6 (Malik et al. 2011).

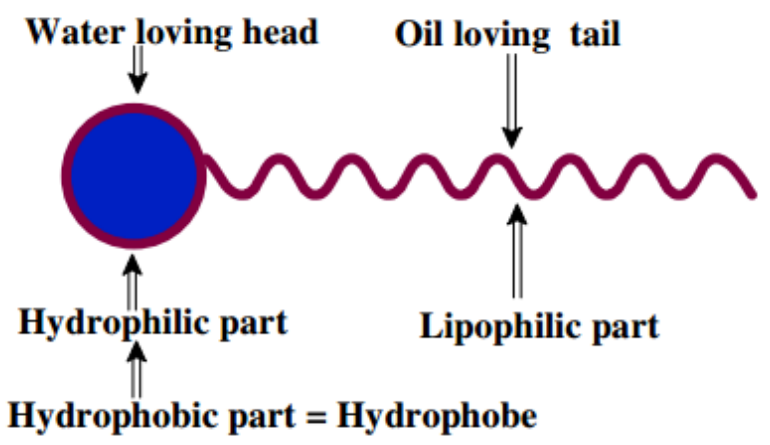

Fig. 1. 6. Schematic diagram of surface-active molecule (Malik et al. 2011).

The surfactants are classified, depending on the charge of head groups, as (Table 1.2):

\subsubsection{Anionic}

They carry negative charge. $60 \%$ of the worldwide production of the surfactants are viscoelastic surfactants and they cost lower compared to the other types. Sodium dodecyl sulfate (SDS) is the most important surfactant in anionic group. 


\subsubsection{Nonionic}

They have no surface charge, therefore, they are compatible with other types and are good candidates to enter complex mixtures. They are good detergents and emulsifiers, also less sensitive to electrolytes.

\subsubsection{Cationic}

The nitrogen atom usually carries the positive charge. They cannot be mixed with anionic surfactants. Therefore, they are not considered good detergents.

\subsubsection{Zwitterionic}

They carry both negative and positive charge. Usually the positive charge is ammonium but the negative source is mostly different. This type of surfactant is used in acid diversion application in oil field industry and they are called 'amphoterics'. They only have their amphoteric characteristics over a certain $\mathrm{pH}$ and the $\mathrm{pH}$ determines which charged group would be dominant.

Table 1. 2. Different types of surfactant (Schramm et al. 2003).

\begin{tabular}{|c|c|c|}
\hline Class & Examples & Structures \\
\hline Anionic & $\begin{array}{l}\text { Na strearate } \\
\mathrm{Na} \text { dodecyl sulfate } \\
\mathrm{Na} \text { dodecyl benzene sulfonate }\end{array}$ & $\begin{array}{l}\mathrm{CH}_{3}\left(\mathrm{CH}_{2}\right)_{16} \mathrm{COO}^{-} \mathrm{Na}^{+} \\
\mathrm{CH}_{3}\left(\mathrm{CH}_{2}\right)_{11} \mathrm{SO}_{4}{ }^{-} \mathrm{Na}^{+} \\
\mathrm{CH}_{3}\left(\mathrm{CH}_{2}\right)_{11} \mathrm{C}_{6} \mathrm{H}_{4} \mathrm{SO}_{3}{ }^{-} \mathrm{Na}^{+}\end{array}$ \\
\hline Cationic & $\begin{array}{l}\text { Laurylamine hydrochloride } \\
\text { Trimethyl dodecylammonium chloride } \\
\text { Cetyl trimethylammonium bromide }\end{array}$ & $\begin{array}{l}\mathrm{CH}_{3}\left(\mathrm{CH}_{2}\right)_{11} \mathrm{NH}_{3}{ }^{+} \mathrm{Cl}^{-} \\
\mathrm{C}_{12} \mathrm{H}_{25} \mathrm{~N}^{+}\left(\mathrm{CH}_{3}\right)_{3} \mathrm{Cl}^{-} \\
\mathrm{CH}_{3}\left(\mathrm{CH}_{2}\right)_{15} \mathrm{~N}^{+}\left(\mathrm{CH}_{3}\right)_{3} \mathrm{Br}^{-}\end{array}$ \\
\hline Non-ionic & $\begin{array}{l}\text { Polyoxyethylene alcohol } \\
\text { Alkylphenol ethoxylate }\end{array}$ & $\begin{array}{l}\mathrm{C}_{\mathrm{n}} \mathrm{H}_{2 \mathrm{n}+1}\left(\mathrm{OCH}_{2} \mathrm{CH}_{2}\right)_{\mathrm{m}} \mathrm{OH} \\
\mathrm{C}_{9} \mathrm{H}_{19}-\mathrm{C}_{6} \mathrm{H}_{4}\left(\mathrm{OCH}_{2} \mathrm{CH}_{2}\right)_{\mathrm{n}} \mathrm{OH}\end{array}$ \\
\hline Zwitterionic & $\begin{array}{l}\text { Dodecyl betaine } \\
\text { Lauramidopropyl betaine } \\
\text { Cocoamido-2-hydroxypropyl sulfobetaine }\end{array}$ & $\begin{array}{l}\mathrm{C}_{12} \mathrm{H}_{25} \mathrm{~N}^{+}\left(\mathrm{CH}_{3}\right)_{2} \mathrm{CH}_{2} \mathrm{COO}^{-} \\
\mathrm{C}_{11} \mathrm{H}_{23} \mathrm{CONH}\left(\mathrm{CH}_{2}\right)_{3} \mathrm{~N}^{+}\left(\mathrm{CH}_{3}\right)_{2} \mathrm{CH}_{2} \mathrm{COO}^{-} \\
\mathrm{C}_{n} \mathrm{H}_{2 \mathrm{n}+1} \mathrm{CONH}\left(\mathrm{CH}_{2}\right)_{3} \mathrm{~N}^{+}\left(\mathrm{CH}_{3}\right)_{2} \mathrm{CH}_{2} \mathrm{CH}(\mathrm{OH}) \mathrm{CH}_{2} \mathrm{SO}_{3}^{-}\end{array}$ \\
\hline
\end{tabular}




\subsubsection{Surfactant micelles size and shape}

Low concentration of the surfactants act like electrolytes in the aqueous solutions. When the concentration increases they show a different behavior and they gather in an organized way and form large molecules that are called micelles. These micelles only form when the surfactant concentration is reached to its critical micelle concentration (CMC). The tail of the surfactants move toward each other and the head group forms an interface with the aqueous surrounding. Micellization process is shown in Fig 1.7.

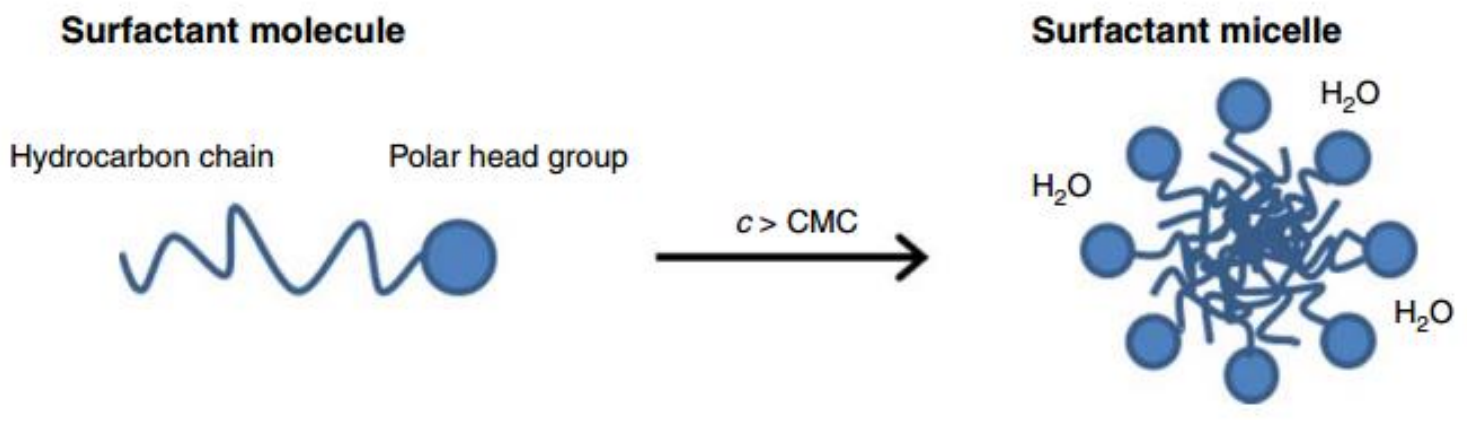

Fig. 1. 7. Micellization process (Hull et al. 2015).

The size and shape of these micelles depend on various surfactant properties such as temperature, ionic strength, type, chain length, and concentration of salt. CMC increases as the size of the polar head group increases in the ionic surfactants, while overcoming the electrostatic repulsion in the head group will be harder. On the other hand increasing the chain length of the surfactant to approximately 16 carbons will decrease the CMC. Molecular packing number is used to predict the micelle structure and is defined as (Hull et al. 2015) (Eq. 3): 
Molecular packing parameter $=\mathrm{V}_{0} / \mathrm{a}_{0} 1_{\mathrm{c}}$

Where $l_{c}$ is the critical chain length, $V_{0}$ is the volume of the hydrocarbon chain or chains, and $\mathrm{a}_{0}$ is the optimal head group area (the surface area per molecule at the interface of water and surfactant). When the packing parameter is less than $1 / 3$, the micelles aggregate spherically, and when it is between $1 / 3$ and $1 / 2$, the micelles will transform to cylindrical (Fig 1.8).
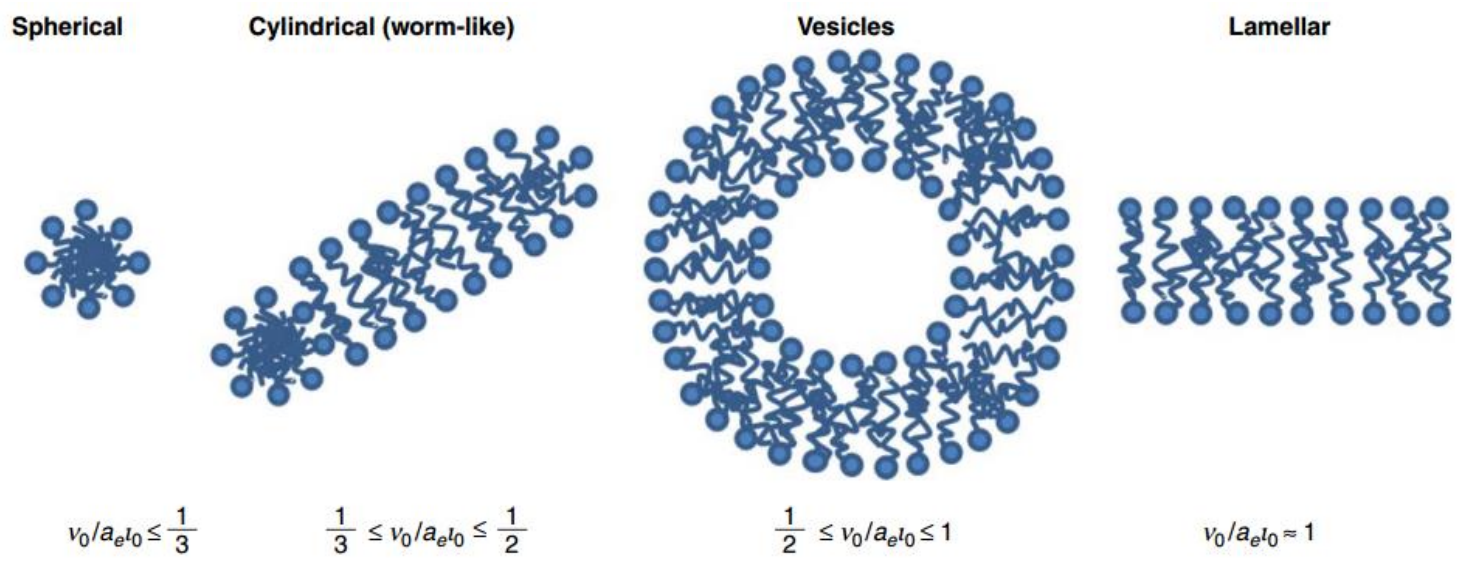

Fig. 1.8. Schematics of the micelles based on molecular packing parameter (Hull et al. 2015).

Therefore, adding salt or increasing the temperature screens the electrostatic interhead group repulsion and thereby reduces the $a_{0}$ and increases the packing number (Israelachvili et al. 1976; Israelachvili 1992). Hence, the micelles will transform from the spherical shape to the elongated rodlike shape, which is more favorable in oilfield applications since they impart viscoelastic property to the fluid. Once the acid reacts with carbonate rocks (Eqs. 2 and 3) and the pH reaches between 2 and 3, the surfactant 
molecules form wormlike micelles that significantly increase the viscosity (Nasr-El-Din et al. 2008).

A detailed study of chemical, structural, and behavioral characteristics of wormlike micelles was reported by Dreiss (2007). Cryo-transmission electron microscopy (cryiTEM), and static light scattering methods was used in this review to investigate an extensive list of surfactant that form wormlike micelles.

\subsection{Impact of Fe(III) on the viscoelastic surfactant-based acids}

Iron contamination is always a great concern in oilfield applications. Fe(II) and Fe(III) ions both can cause formation damage. They can come directly from iron minerals that are present in the formation or from the tank the solution was mixed in or finally from the tubular (Hall and Dill 1988). Taylor et al. (1999) reported the solubility of some iron compound in acid and precipitation of $\mathrm{Fe}(\mathrm{III})$ hydroxide in sweet wells at a $\mathrm{pH}$ of nearly 1 and completes at a $\mathrm{pH}$ of approximately 2 at $25^{\circ} \mathrm{C}$. Fe(II) is not considered a problem since it starts to precipitate when the $\mathrm{pH}$ value is higher than 6.5 (Dill and Smolarchuk 1988). Although, the same Fe(II) will precipitate in the existence of hydrogen sulfide in sour wells (Walker et al. 1991).

In one of the field studies of the VES-based acid 10,000 mg/L iron contamination was reported in the acid analysis, which caused the treatment to fail (Al-Nakhli et al. 2008). Also 200 to 3,500 mg/l iron content was reported from the wellhead (Gougler et al. 1985). In VES-based acid solutions, VES will interact with Fe(III) and precipitate. Shu et al. (2015) reported the precipitation of two VES formulations in $20 \mathrm{wt} \% \mathrm{HCl}$ at room 
temperature. The first VES started losing viscoelastic properties by adding 1,500 ppm iron, and the second VES, which had a stronger anionic group in its head group, also started precipitating at iron concentration of higher 6,000 ppm. Al-Nakhli et al. (2008) also highlighted the precipitation of amphoteric and cationic VES with the addition of iron.

There are some attempts to minimize iron contamination of the injected acid, such as using chelating agents to prevent the interaction of the Fe(III)/VES (Shu et al. 2016). The previous two researchers investigated only the interaction of the VES and Fe(III) at room temperature and live acid conditions, but as a known fact, the VES-based solution will be spent after contacting the formation, and it will encounter high temperatures.

\subsection{Chelating agents}

Chelating agents are organic compounds that contain two or more electron donating groups. These groups function as Lewis bases that form coordination bonds form a single molecule results in the formation of one or more heterocyclic ring or cheated rings, hence the name chelating agents. The strength of chelating agents is typically measured by its stability constant with the ion of interest. Generally, if a chelating agent exhibits higher stability with Fe(III), for example, than another chelating agent, it will also show higher stability with other ions compared to that same chelating agent. Lastly, in oil and gas industry, it should be noted that the term 'chelating agents' is typically used to refer to a specific sub group of chelating agents known as aminopolycarboxylic acids. A 
brief review of chemistry and dissolution mechanism of these chelating agents was presented in this study.

\subsubsection{Aminopolycarboxylic acids (APCAs)}

As the name aminopolycarboxylic acids implies, this subgroup of chelating agents contains one or more nitrogen groups as well as multiple carboxylic acid functional groups. The nitrogen group is typically located at the center of the molecule while the carboxylic acid groups behave like 'arms' of the chelating agent by 'grabbing' the ion form solution. This process of grabbing ions from the solution is also known as chelation and results in the formation of a stable complex that isolates the grabbed ion from further reactions. The stability of the formed complex is dependent on the function of the size of the ring formed during chelation, the number of the rings formed, the basicity of the chelating agent, the central metal atom, and the nature of the donor atoms (Mellor and Dwyer 1964).

Chemical structures of chelating agents commonly used in the oil and gas industry for scale removal are shown in Fig 1.9. 

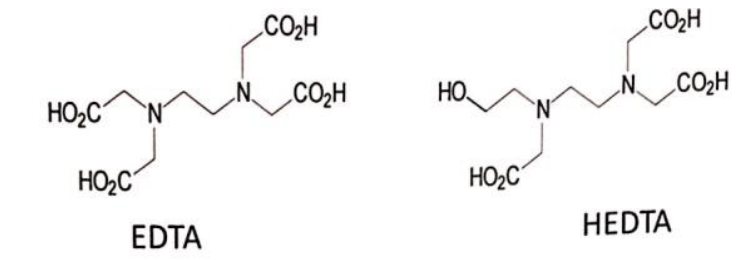

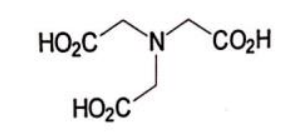

NTA<smiles>O=C(O)CN(CCO)CC(=O)O</smiles>
HEIDA<smiles>O=C(O)CN1CCN(CC(=O)O)CCN(CC(=O)O)CCN(CC(=O)O)CC1</smiles>

DOTA<smiles>O=C(O)CN(CCN(CC(=O)O)CC(=O)O)CCN(CC(=O)O)CC(=O)O</smiles><smiles>O=C(O)CCC(C(=O)O)N(CC(=O)O)CC(=O)O</smiles><smiles>O=C(O)CN(CC(=O)O)C1CCCCC1N(CC(=O)O)CC(=O)O</smiles>

Fig. 1.9. Aminocarboxylic acids chemical structure.

\subsubsection{EDTA (Ethyene diamine tetraacetic acid)}

EDTA is hexadentate aminopolycarboxylic, which was originaly patented in 1935 in Germany by Manuz, F. and has been used in a variety of application ranging from detergents to textiles (Oviedo and Rodríguez 2003). However, despite its wide range of applications and common use, EDTA presents several problems. Firstly, it is not readily bioegradable. And its use is prohibited in some countries (Kolodynska et al. 2009). Secondly, it has low solubility in acid solutions because of its ampholytic nature (Martell 
and Calvin 1952). Theses disadvantages have spurred researches to search for alternative chelating agents.

\subsubsection{GLDA (L-Glumatic acid N, N-diacetic acid)}

GLDA, is a relatively new chelating agent (Heus 2013). GLDA is used for iron control as well as stimulation of carbonate and sandstone reservoir. It has high solubility in both water and highly concentrated acid solutions (LePage et al. 2011). This is because of the larger groups attached to the iminodiacetic acid part which reduces the likelihood of crystallization and therefore increasing solubility (De Wolf et al. 2014). Furthermore, it is readily biodegradable as it is manufactured from L-glumatic acid. In terms of stability constants, those of GLDA have been found to be lower than the EDTA and HEDTA (Begum et al. 2012).

\subsubsection{HEDTA (Hydroxyethyl ethylene diamine triacetic acid)}

HEDTA was suggested by Frenier et al. (Frenier et al. 2003) to replace EDTA as a stimulation fluid. This was due to the low solubility of the EDTA with the only difference being that it has a hydroxyethyl group in place of one acetic acid group. The addition of

the hydroxyethyl group improves the solubility of HEDTA, but lowers its stability constant. HEDTA has also been used for iron control as well as scale removal (Frenier 1986; Frenier 2001). However, it faces similar biodegradability issues as EDTA due to the presence of two nitrogen atoms in its structure. 


\subsubsection{HEIDA (Hydroxyl Iminodiaceticacid) or HIDA}

HEIDA has been used for a variety of purposes including scale removal, and acidizing (Frenier et al. 2004). It is a tridentate chelating agent with a structure similar to nitrilotriacetic acid (NTA) except it has only 2 acetate groups and a hydroxyethyl group. The advantage of HEIDA is its biodegrability and it is solubility which made it possible candidate for replacing EDTA. HEIDA is also one of the main thermal degradation products of EDTA (Motekaitis et al. 1982).

\subsubsection{DTPA (Diethylene triamine pentaacetic acid)}

DTPA is an octadentate chelating agent that also has the highest stability constants among commonly used chelating agents in the petroleum industry. Its most common application in the industry being $\mathrm{BaSO}_{4}$ and $\mathrm{SrSO}_{4}$ scale removal (Putnis et al. 1995). However, DTPA is not readily biodegradable (Sýkora et al. 2001), and has solubility issues in water and acid solution.

\subsubsection{DOTA (1,4,7,10-tetraazacyclododecane-1,4,7,10-tetraacetic acid)}

DOTA is a macrocyclic, octadentate chelating agent that has seen significant uses in the medical industry. It is often used to chelate lanthanides due to the high thermal stability and kinetic inertness of the complex formed. 


\subsubsection{CDTA (trans-l,3-cyclohexylenediaminetetraacetic acid)}

CDTA is a hexadentate chelating agent that is also commonly used in the medical industry alongside DOTA. In the petroleum industry, it has been tested as an alternate acidizing fluid for carbonate formations (Fredd and Fogler 1997). Due to the cyclohexane group, CDTA is lipophilic in addition to being hydrophilic. This property makes it more effective at alleviating nickel induced alterations in the body than other chelating agents that are only hydrophilic (Misra et al. 1988).

In this study, two types of chelating agents were used: GLDA and HEDTA as an iron control agent (ICA). Li et al. (Li et al. 2011) showed that the efficiency of spent VES solution is adversely affected by seven different chelating agents in low-temperature range of $\left(80-180^{\circ} \mathrm{F}\right)$. They observed a reduction in the viscosity of the VES-base acid by adding the chelating agents. Therefore, an important aspect which has not been considered yet, is how the ICA can assist to eliminate the iron contamination effect on VES, while it reduces the viscosity properties of the VES by itself.

\subsection{Research objectives}

1. Finding a stable VES for high temperature wells; Since More than $60 \%$ of the world's oil remains in carbonates and some of them are high temperature reservoirs $\left(>130^{\circ} \mathrm{C}\right)($ Lu et al. 2014).

2. Studying how ICA can assist to eliminate the effect of iron contamination on VES, while ICA reduces the viscosity properties of the VES. 
3. Investigating the effect of different preparation methods of spent acid on the apparent viscosity of the VES-based solution. Since VES-based acids $\mathrm{pH}$ will increase after the solution reaches the formation and the acid will be spent.

4. Studying the effect of Fe(III) and ICA separately on the viscosity of an amphoteric VES in spent conditions over a temperature range of $80-400^{\circ} \mathrm{F}$.

5. Studying the interaction of chelating agents and Fe(III) in spent VES-based acid solutions and their effects on viscosity of the VES. 


\section{CHAPTER II}

\section{EXPERIMENTAL STUDIES}

\subsection{Materials}

The viscoelastic surfactant used in this study has a strong anionic head group, and the proposed general formula for the VES is shown in Fig. 2.1. The gelling agent disclosed and described in this study is surfactant that can be added singly or it can be used as a primary component in the aqueous compositions. Erucamidopropyl hydroxyethyl sulfobetaine is one the groups observed in the VES, although the full description of all of the used gelling agent groups in this surfactant is disclosed.

However, a close example of the surfactant preparation procedure was mentioned in the patent by Gadberry (Gadberry et al. 2012), sodium 3-chloro-2-hydroxy-1propanesulfonate is reacted with erucamidopropyl hydroxypropylsulfobetaine, N-(3dimethylaminopropyl) erucamide in the presence of SCA 40B ethanol, propylene glycol, deionized water, and $\mathrm{NaOH}$ under $\mathrm{N}_{2}$. To reduce the amine salt and free amine concentration existing in the mixture to lower than $1 \%$ the mixture should be heated approximately to $113^{\circ} \mathrm{C}$ and continuously stirred. If the amine concentration is still higher than $1 \%, \mathrm{NaOH}$ is used to eliminate it. When the free amine and amine salt content in the mixture was confirmed to be negligible, we start the cooling process until $60^{\circ} \mathrm{C}$ and remove the pressure over the sample. In the final step to remove the salts, a batch of water concentration approximately around $17.5 \%$ was added to the solution. 


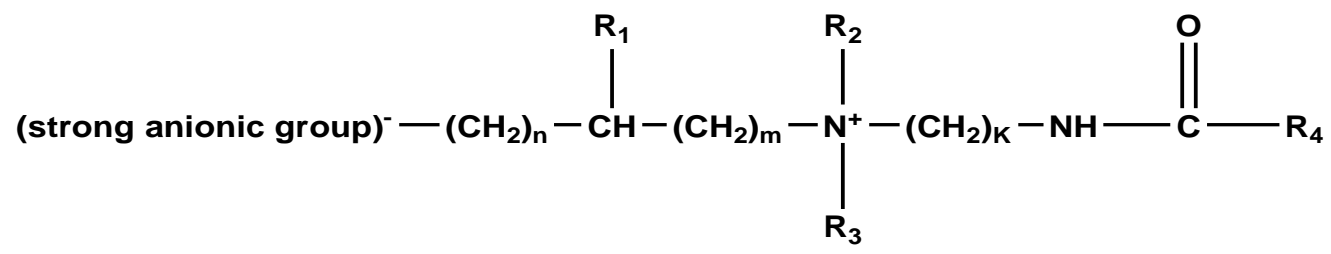

Fig. 2. 1. Molecular structure of the VES.

In which the ionic group cannot be protonated even under strong acidic conditions. R4 is saturated or unsaturated and is a hydrocarbon group of approximately 17 to 29 carbon atoms. R2 and R3 are each independently selected from a straight chain or branched and are made up of an alkyl or hydroxyalkyl group with 1 to approximately 6 carbon atoms. $\mathrm{R} 1$ is selected from $\mathrm{H}$, hydroxyl, alkyl, or hydroxyalkyl group from 1 to 4 carbon atoms; $\mathrm{k}$ is an integer from 2 to $20 ; \mathrm{m}$ is an integer 1 to 20 ; and $\mathrm{n}$ is an integer from 0 to 20 (Gadberry et al. 2012).

Ferric chloride (anhydrous and $97 \mathrm{wt} \%$ active) and the concentrated hydrochloric acid $(36.5 \mathrm{wt} \% \mathrm{HCl})$ used in this study are American Chemical Society (ACS) grade. Chelating agents GLDA-Na $a_{4}$ and HEDTA-Na 3 were used as ICA and their structure is shown in Fig 2.2. Their measured properties are presented in Table 2.1. 

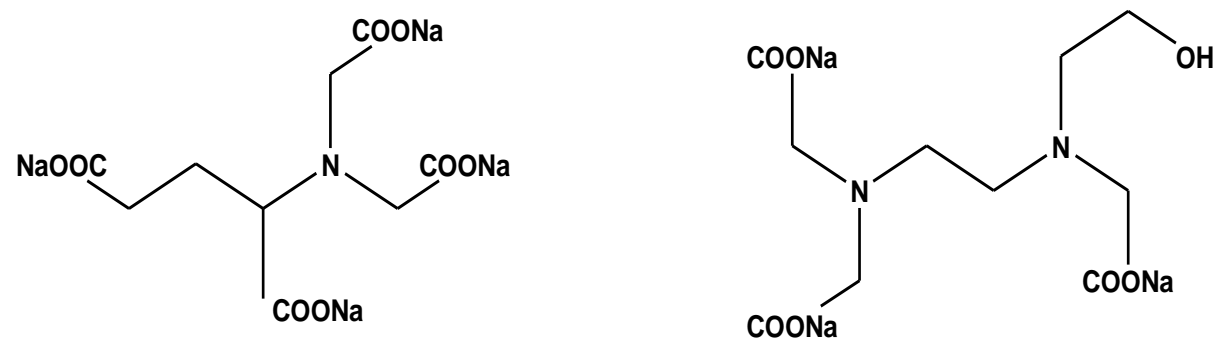

Fig. 2.2. Molecular structures of GLDA-Na (left) and HEDTA-Na 3 (right). (LePage et al. 2011).

Table 2. 1. Properties of the chelating agents, as received at $20^{\circ} \mathrm{C}$.

\begin{tabular}{|c|c|c|c|}
\hline Chelant & Concentration, wt\% & pH & Density $(\mathrm{g} / \mathrm{cm})$ \\
\hline GLDA-Na4 & 47.4 & 13.72 & 1.4158 \\
\hline HEDTA-Na3 & 42.5 & 13.28 & 1.280 \\
\hline
\end{tabular}

Calcium carbonate (ACS grade) was used to neutralize the live acid, and calcium chloride dihydrate (ACS grade) was also used to prepare a simulated spent acid. Corrosion inhibitor A-5300 was used as we received it from Well Services Group Company. The composition of this chemical is reported in Table 2.2. This corrosion inhibitor was specially designed to work with the viscoelastic surfactant used in this study. 
Table 2. 2. Corrosion Inhibitor A-5300 composition.

\begin{tabular}{ccc}
\hline Component name & Molecular weight \% & CAS number \\
\hline Formic acid & $50-60$ & $64-18-6$ \\
Surfactant & $5-10$ & Trade secret \\
Ethanol & $1-5$ & $64-17-5$ \\
\hline
\end{tabular}

\subsection{Equipment}

A high- pressure high-temperature (HP/HT) Rheometer was used to measure the apparent viscosity of the spent VES-based acid solutions at temperatures in the range of 80 to $400^{\circ} \mathrm{F}$, pressure of $350 \mathrm{psi}$ and shear rate of $100 \mathrm{~s}^{-1}$. Bob (B5) and the cup of the viscometer made of Hastelloy C-276 to resist corrosion. A detailed experimental procedure is presented for this equipment in Appendix A.

The $\mathrm{pH}$ of the solutions was measured by an Oaktan $\mathrm{pH} 510$ meter, which we calibrated with standard solutions with the $\mathrm{pH}$ of 10, 7, and 4 (Fig. 2.3). 


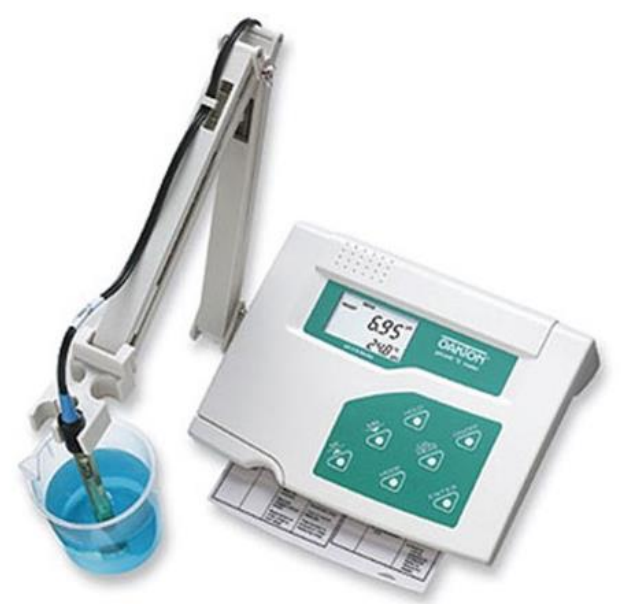

Fig. 2.3. Oaktan pH 510 meter.

Chelating agents GLDA-Na4 and HEDTA-Na3 densities were measured by an Anton Paar, DMA 4100 model (Fig. 2.4).

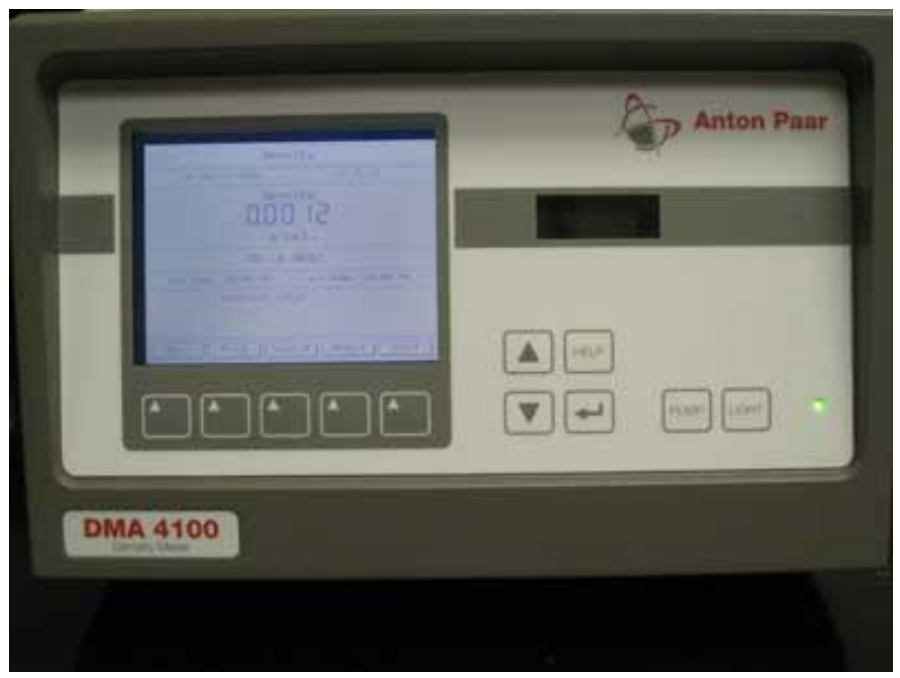

Fig. 2.4. Anton Paar DMA 4100. 
Mechanical overhead agitator was used to prepare the VES-based acid solution. The VES was added drop by drop to the vortex of the mechanical overhead agitator (Fig. 2.5). The blades of the agitator are coated with a polymer face to avoid the reaction between live $\mathrm{HCl}$ acid and blade.

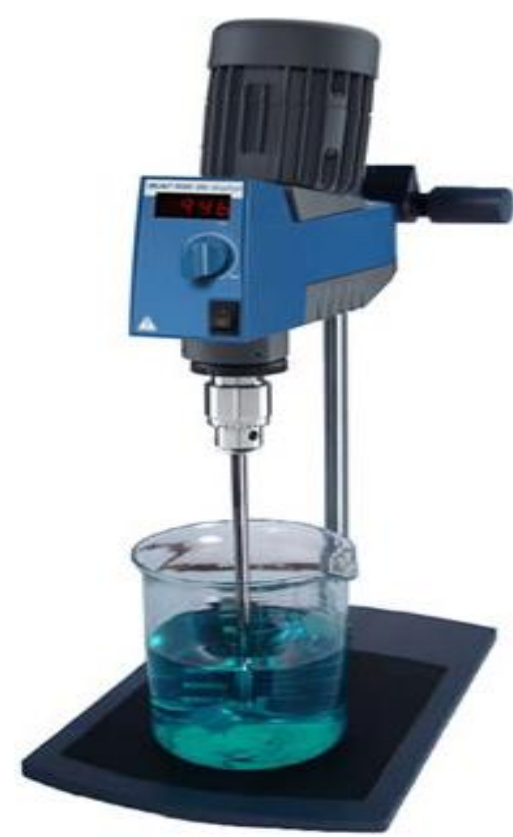

Fig. 2.5. Mechanical overhead agitator.

Model Z206A, centrifuge was used to remove the air bubbles in the viscous spent acids, 10 minutes at $3000 \mathrm{rev} / \mathrm{min}$ for each sample (Fig. 2.6). 


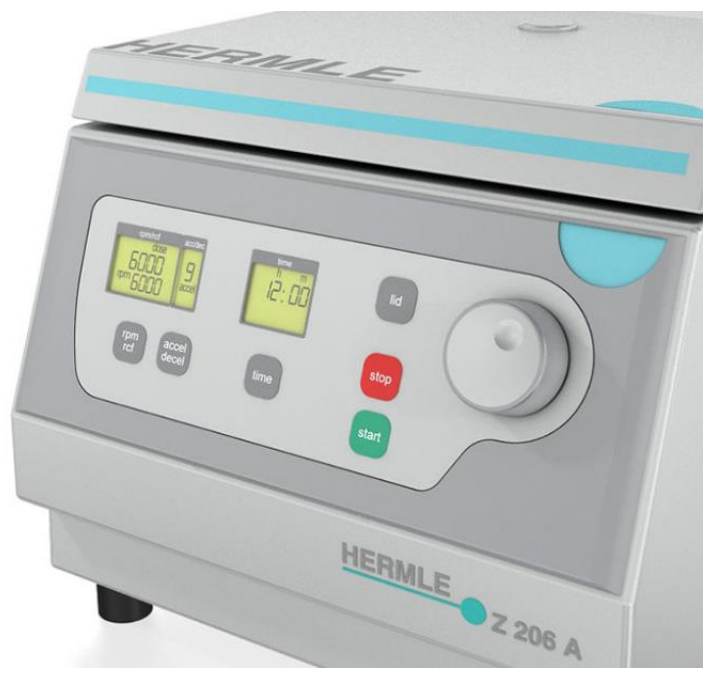

Fig. 2.6. Centrifuge Z206 A.

The thermal stability tests were conducted by the HP/HT see-trough cell illustrated in Fig 2.7. 


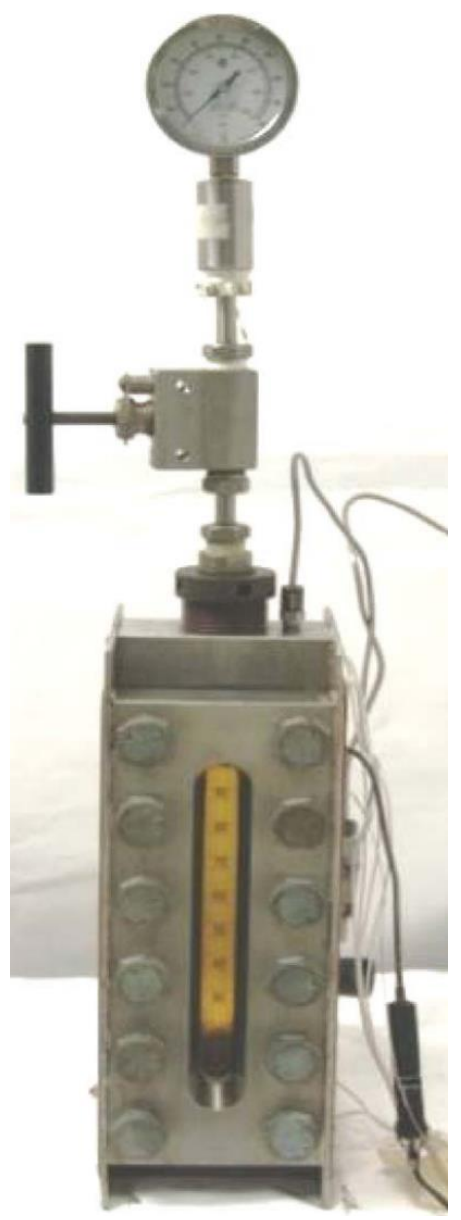

Fig. 2.7. HP/HT see-through cell equipment.

\subsection{Sample preparation}

All of the experiments described in this thesis were conducted using $20 \mathrm{wt} \% \mathrm{HCl}$ and $5 \mathrm{vol} \%$ of the VES as it was received. Different concentration $(1,000-10,000 \mathrm{ppm})$ of $\mathrm{Fe}(\mathrm{III})$ were added to live and spent $20 \mathrm{wt} \% \mathrm{HCl}$ and 5 vol\% VES and three concentrations $(0.010,0.053$, and $0.107 \mathrm{~mol} / \mathrm{L})$ of GLDA and HEDTA were added to spent $20 \mathrm{wt} \% \mathrm{HCl}$ and 5 vol\% VES. Finally, the combination of Fe(III) and chelating agent were added to spent $20 \mathrm{wt} \% \mathrm{HCl}$ and 5 vol\% VES. 


\section{CHAPTER III}

\section{EFFECT OF DIFFERENT PREPARATION METHODS OF SPENT ACID ON THE APPARENT VISCOSITY OF THE VES-BASED SOLUTION}

\subsection{Sample preparation}

\subsubsection{Stability measurement samples}

The mixture of the VES and live $20 \mathrm{wt} \%$ acid was prepared for the see-through cell.

1. $54.7 \mathrm{~cm}^{3}$ of $36.5 \% \mathrm{HCl}$ was separated and transferred to a beaker.

2. 2 vol\% corrosion inhibitor A-5300 was added to the solution.

3. Enough calculated deionized (DI) water was added to $\mathrm{HCl}$ to prepare a 100 $\mathrm{cm}^{3}$ of $20 \mathrm{wt} \% \mathrm{HCl}$.

4. $5 \mathrm{~cm}^{3}$ of the VES was added drop by drop to the vortex of the mechanical agitator while it was mixing. (Fig 3.1). 


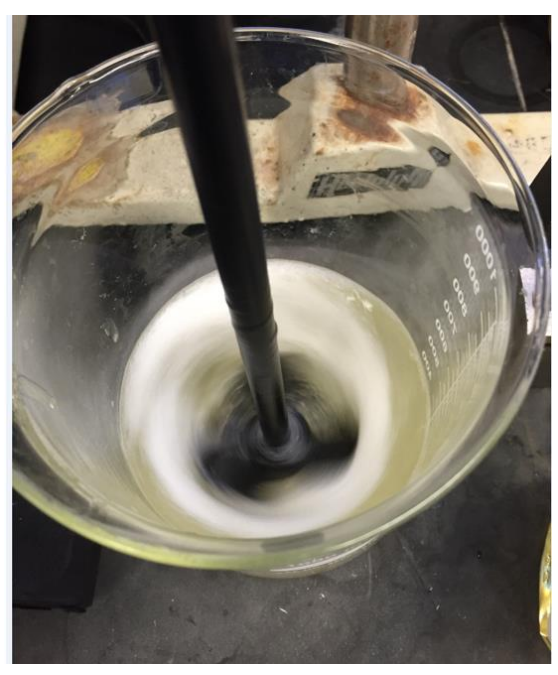

Fig. 3.1. Solution mixture in the mechanical agitator.

\subsubsection{Viscosity measurement samples}

Three methods to prepare spent surfactant-based acids were proposed by Nasr-ElDin et al. (2008), but up to now, no attempt has been made to compare them. Therefore, in order to be able to compare the results of these methods, three types of spent acid samples were prepared as follows:

\section{Method 1:}

5. $54.7 \mathrm{~cm}^{3}$ of $36.5 \% \mathrm{HCl}$ was separated and transferred to a beaker.

6. Enough calculated deionized (DI) water was added to $\mathrm{HCl}$ to prepare a 100 $\mathrm{cm}^{3}$ of $20 \mathrm{wt} \% \mathrm{HCl}$.

7. $5 \mathrm{~cm}^{3}$ of the VES was added drop by drop to the vortex of the mechanical agitator while it was mixing. 
8. $\mathrm{CaCO}_{3}$ were finally added slowly while mixing the solution by the mechanical agitator until it reached $\mathrm{pH}$ of 4.5 .

9. The bubbles produced from the trapped $\mathrm{CO}_{2}$ was removed using 10 minutes of centrifugation at $3,000 \mathrm{rev} / \mathrm{min}$.

\section{Method 2:}

1. $100 \mathrm{~cm}^{3}$ simulated spent acid was prepared by adding $43.11 \mathrm{~g}$ of $\mathrm{CaCl}_{2} \cdot 2 \mathrm{H}_{2} \mathrm{O}$ to $84 \mathrm{~cm}^{3} \mathrm{H}_{2} \mathrm{O}$.

2. The $\mathrm{pH}$ was measured.

3. $5 \mathrm{ml}$ VES was added slowly to the vortex of the solution.

4. The $\mathrm{pH}$ was measured again.

5. To adjust the spent acid $\mathrm{pH}$ value to 4.5 , a few drops of $20 \mathrm{wt} \% \mathrm{HCl}$ were added to the solution.

Method 3:

1. $54.7 \mathrm{~cm}^{3}$ of $36.5 \% \mathrm{HCl}$ was separated and transferred to a beaker.

2. Enough calculated deionized (DI) water was added to $\mathrm{HCl}$ to prepare a 100 $\mathrm{cm}^{3}$ of $20 \mathrm{wt} \% \mathrm{HCl}$.

3. Approximately $29 \mathrm{~g}$ of $\mathrm{CaCO}_{3}$ was added slowly to the solution until the $\mathrm{pH}$ of 4.5 was achieved.

4. $5 \mathrm{~cm}^{3}$ viscoelastic surfactant was added at the last step to the solution (drop by drop to the vortex of the mechanical agitator while it was mixing). 
The first preparation method of the spent VES-based acid is the most time consuming of all methods as observed in the laboratory. While the reaction between $\mathrm{CaCO}_{3}$ and $\mathrm{HCl}$ produces $\mathrm{CO}_{2}$ gas (Eq. 1.1) which will create a foaming solution and extensive mixing is required to eliminate the trapped $\mathrm{CO}_{2}$. Method two consumes the least chemical and it is less time consuming.

\subsection{Results and discussions}

\subsubsection{Thermal stability measurement}

The thermal stability of the live acid is measured with a HP/HT see-through cell, in order to see the stability of the VES after heating for a 6-hour period. Fig 3.2 illustrates the chemical mixture from the see-trough cell under $200^{\circ} \mathrm{F}$ temperature and 400 psi pressure. 


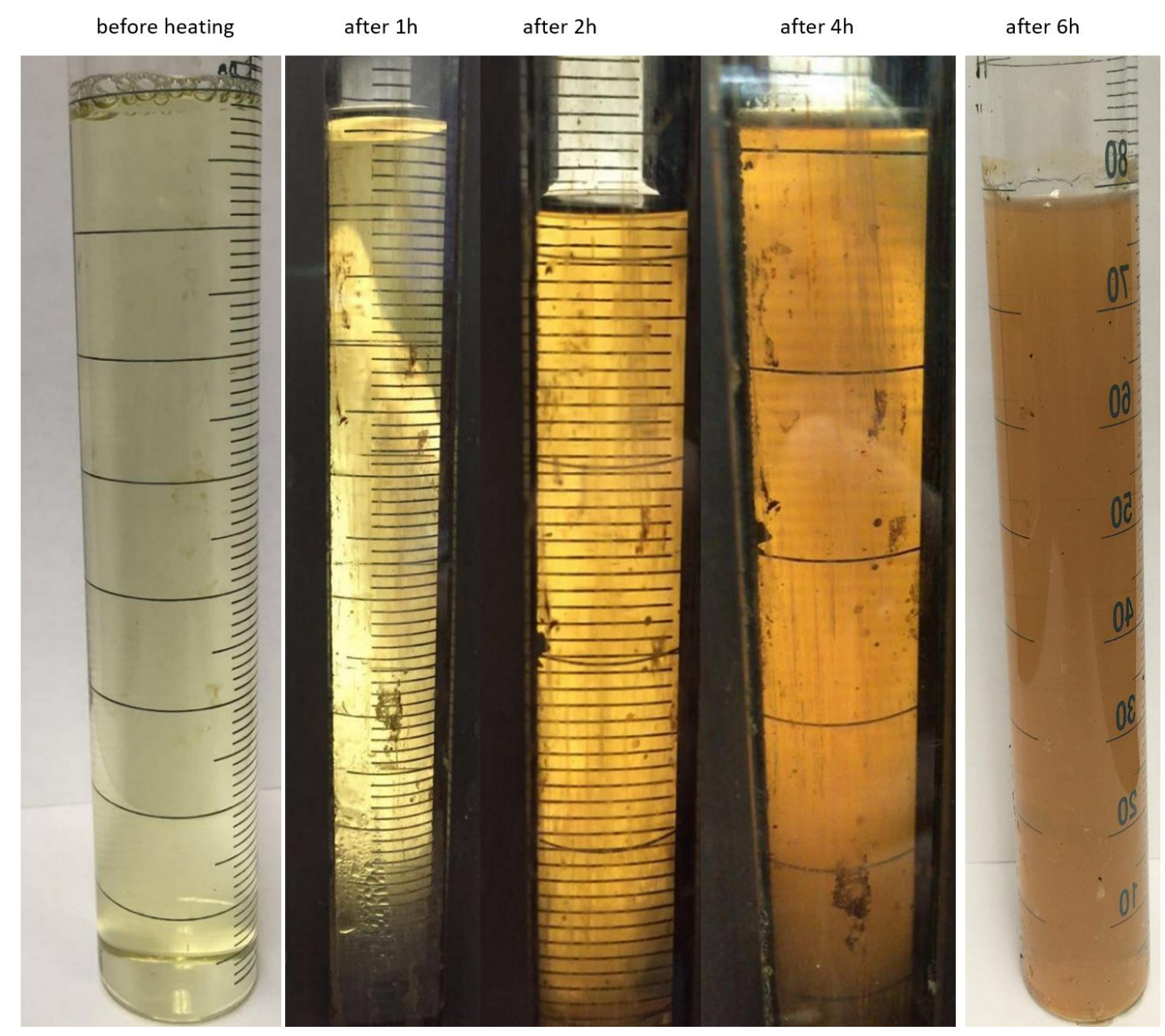

Fig. 3.2. Thermal stability of 5 vol $\%$ VES, 2 vol $\%$ corrosion inhibitor, and $20 \mathrm{wt} \% \mathrm{HCl}$ at $200^{\circ} \mathrm{F}$ and 400 psi for 6 hours.

Visual observation shows no precipitation or phase separation in the solution after heating. The only noticeable difference is the solution color which relates to the corrosion inhibitor. A viscosity test was conducted on the live acid before and after the treatment at room temperature (Fig. 3.3). The VES solution maintains its viscosity after 6-hours of 
heating. The slight viscosity increase after the heating is the effect of temperature on the VES-based solution which increases the viscosity.

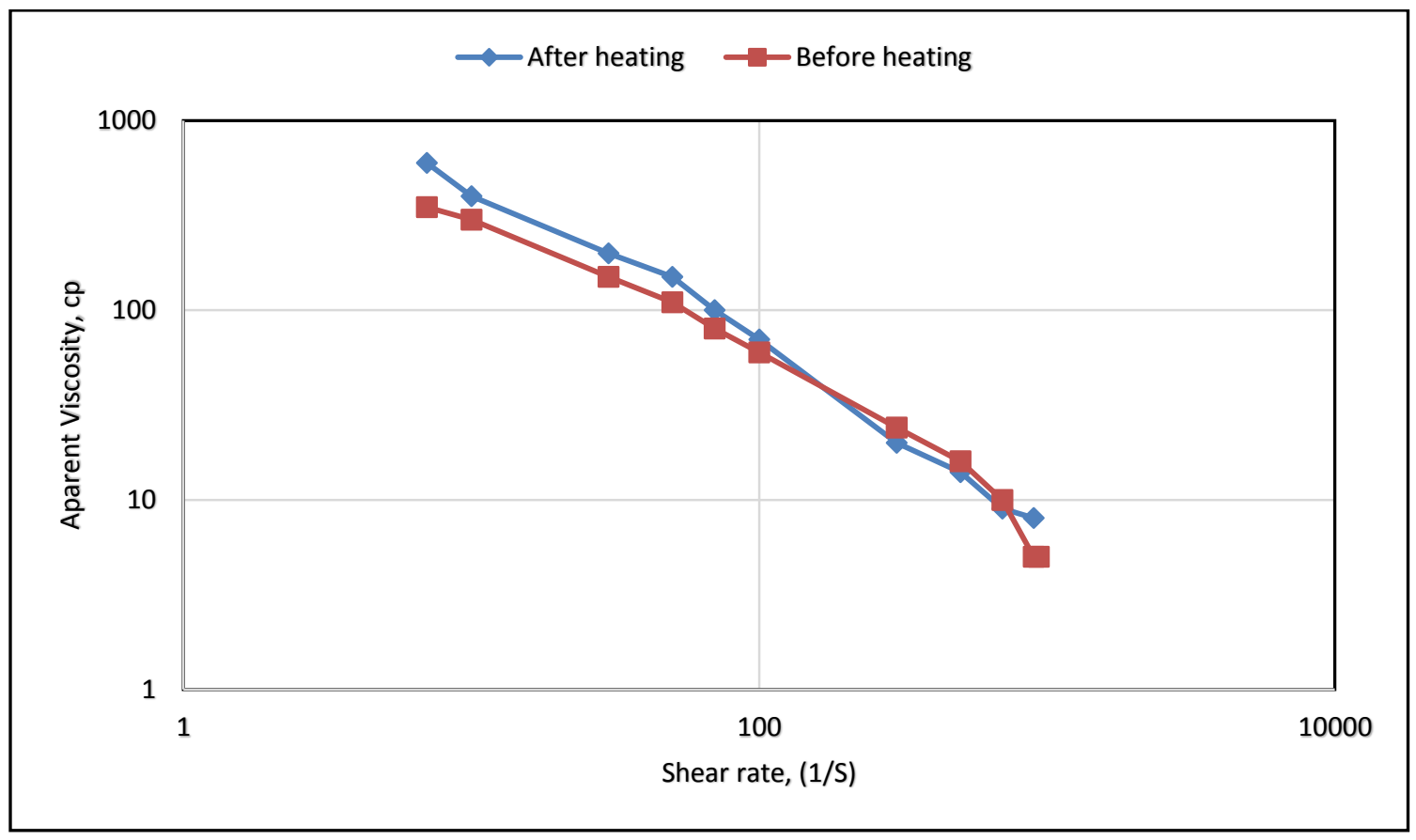

Fig. 3.3. Viscosity versus shear rate of the VES solution (5 vol\% VES, 2 vol\% corrosion inhibitor, and $20 \mathrm{wt} \% \mathrm{HCl}$ ) at $77^{\circ} \mathrm{F}$ and 300 psi before and after heating.

\subsubsection{Rheology study on the spent VES-based acid}

Viscoelastic properties of the spent VES-based solutions are crucial aspects, which should be studied prior to any use of the solution as a diverting agent in industry. The viscoelastic surfactant examined in this study is a new amphoteric surfactant introduced to the oil and gas industry which had an implacable tolerance to temperature, especially compared to other viscoelastic surfactants used previously in stimulating carbonate reservoirs. The maximum temperature reported for spent VES-based acid (used as 
diverting agent) that can maintain its viscosity above $70 \mathrm{cp}$ is $280^{\circ} \mathrm{F}$ ( $\mathrm{Li}$ et al. 2011 ; NasrEl-Din et al. 2008; Hanafy et al. 2016; Sullivan et al. 2007).

As Fig.3.4 indicates, apparent viscosity of the spent VES-based solution increased with the temperature until it reached about $220^{\circ} \mathrm{F}$. This increase is according to micelles structure transforming from vesicles rings toward more cylinders (Bhargava et al. 2007) At higher temperatures between 220 and $260^{\circ} \mathrm{F}$, the apparent viscosity reduced from 380 to $210 \mathrm{cp}$. Then, the viscosity started to increase again after $260^{\circ} \mathrm{F}$ and had a second rise and decline and still remains above $100 \mathrm{cp}$ until $400^{\circ} \mathrm{F}$. This second rise in viscosity (second peak) with temperature increase, could be a result of the structure of the rodlike micelle. In certain temperatures branched wormlike micelles were formed and suddenly decreased the viscosity due to the molecular-packing parameter. As the temperature increases, the second rise in viscosity has a similar mechanism to the first peak (Yang et al. 2015). The breaking mechanism for this VES was studied by Fogang et al. (Fogang et al. 2016) with three different oils. The low molecular weight oil, n-decane broke the viscoelastic surfactant solution at low and high temperature $\left(86\right.$ and $\left.140^{\circ} \mathrm{F}\right)$. higher molecular weight oils, crude oil, and extra virgin olive oil broke the solution high temperature $\left(140^{\circ} \mathrm{F}\right)$. Generally, n-decane (low molecular weight oils) are more efficient in both high and low temperatures. On the other hand, the high molecular weight oils (crude oil and extra virgin olive oil) are more efficient at higher temperature.

Spent VES-based acid was prepared by three different methods explained earlier. Fig. 3.4 compares their apparent viscosities, which was measured at a shear rate of $100 \mathrm{~s}^{-1}$ and over temperature range of 80 to $400^{\circ} \mathrm{F}$. A $100 \mathrm{~s}^{-1}$ shear rate is considered a 
high shear rate in rheological study for the viscoelastic surfactants. Most of the VES available in market cannot tolerate this high shear rate and break in early stages. The presented VES obtains high viscosity is this shear rate with only 5 vol\%, which is another noticeable advantage (Fig. 3.4).

As it can be seen in Fig. 3.4, although the preparation methods varies from each other, the outcome of their apparent viscosity is almost the same. The only noticeable difference is between method 1 and the other two methods in temperatures below $120^{\circ} \mathrm{F}$. For method 1, the viscosity is nearly $50 \mathrm{cp}$ from the beginning, while for other methods, the apparent viscosity built up as the temperature increased gradually. Temperature and salt concentrations are the two most effective factors in changing the apparent viscosity of the VES-based solution. All three samples have the same concentration of $\mathrm{CaCl}_{2}$ but, based on Eq. 1, $\mathrm{CaCl}_{2}$ is (i) highly water soluble, (ii) dissolves in water in an exothermic manner, (iii) releases a large amount of heat, which increases the temperature and causes the head group area size of the VES $\left(a_{0}\right)$ to reduce again and eventually increases the viscosity of the solution (Hull et al. 2016).

Method 1, is the only method where the acid solution contains the VES when it was gradually neutralized by the $\mathrm{CaCO}_{3}$; therefore, it can be seen that increasing temperature in early stages caused an increasing trend in the apparent viscosity of the VES-based solution compared to the other two methods. Based on sample preparation procedures the final rheology study which shows similar outcome viscosity for the VES, We suggest the second method of spent acid preparation for future laboratory studies in 
this area, since this method is less time consuming and more economical compared to other two methods.

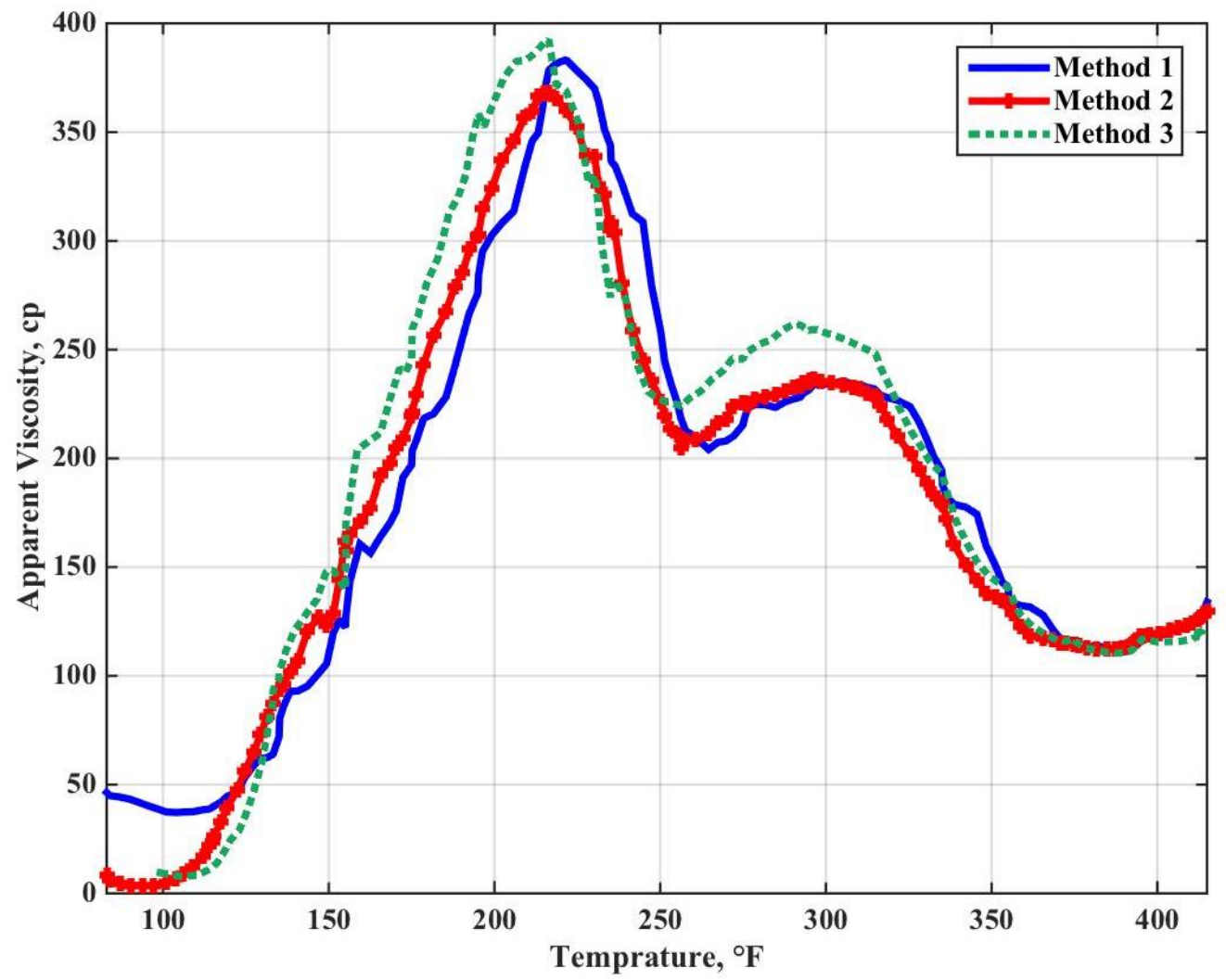

Fig. 3.4. Effect of the three different methods of spent VES solution preparation (spent 20 $\mathrm{wt} \% \mathrm{HCl}$ and $5 \mathrm{vol} \% \mathrm{VES}$ ) on their apparent viscosities at $350 \mathrm{psi}$ and a shear rate of 100 $\mathrm{s}^{-1}$. 


\section{CHAPTER IV}

\section{EFFECT OF DIFFERENT CONCENTRATIONS OF FE (III) ON THE LIVE AND SPENT VES-BASED SOLUTIONS}

\subsection{Sample preparation}

\subsubsection{Live VES-based acid preparation with different concentrations of iron (III)}

1. $54.7 \mathrm{~cm}^{3}$ and $41 \mathrm{~cm}^{3}$ of $36.5 \% \mathrm{HCl}$ was separated and transferred to a beaker.

2. Enough calculated deionized (DI) water was added to $\mathrm{HCl}$ to prepare a 100 $\mathrm{cm}^{3}$ of $20 \mathrm{wt} \% \mathrm{HCl}$ and $15 \mathrm{wt} \% \mathrm{HCl}$.

3. $5 \mathrm{~cm}^{3}$ of the VES was added drop by drop to the vortex of the mechanical agitator while it was mixing.

4. Different concentration of Fe(III) from 1,000 to 10,000 ppm was added to the solution in the form of Ferric chloride.

5. The bubbles produced from the trapped $\mathrm{CO}_{2}$ was removed using 10 minutes of centrifugation at 3,000 rev/min.

\subsubsection{Spent VES-based acid preparation with different concentrations of iron (III)}

1. $54.7 \mathrm{~cm}^{3}$ of $36.5 \% \mathrm{HCl}$ was separated and transferred to a beaker.

2. Enough calculated deionized (DI) water was added to $\mathrm{HCl}$ to prepare a 100 $\mathrm{cm}^{3}$ of $20 \mathrm{wt} \% \mathrm{HCl}$.

3. $5 \mathrm{~cm}^{3}$ of the VES was added drop by drop to the vortex of the mechanical agitator while it was mixing. 
4. Different concentration of Fe(III) from 1,000 to 10,000 ppm was added to the solution in the form of Ferric chloride.

5. $\mathrm{CaCO}_{3}$ were finally added slowly while mixing the solution by the mechanical agitator until it reached $\mathrm{pH}$ of 4.5 .

6. The bubbles produced from the trapped $\mathrm{CO}_{2}$ was removed using 10 minutes of centrifugation at 3,000 rev/min for 10 minutes.

\subsection{Results and discussions}

To better understand the interaction between VES and Fe(III) in spent acid conditions, we started from live acid condition with $20 \mathrm{wt} \%$ of $\mathrm{HCl}$. This concentration of $\mathrm{HCl}$ is chosen since the carbonate acidizing is conducted in it. The solution color was yellow, in low iron concentrations $(1,000-3,000 \mathrm{ppm})$ and it became darker and more viscous as the concentration of Fe(III) was increased. Fig 4.1. shows that when the Fe(III) concentration was less than 5,000 ppm, no phase separation was observed. However, at Fe(III) concentration of $6,000 \mathrm{ppm}$ and higher $(10,000 \mathrm{ppm})$, phase separation was observed, and a brown precipitate was formed at the bottom of the tube. Shu et al. (2016) studied the brown precipitate that appeared at the bottom of the tube and the supernatant by the inductively coupled plasma and proposed that the brown gel-liked material is mostly $\mathrm{Fe}(\mathrm{III})$ interacting with the viscoelastic surfactant and precipitating; while the supernatant above the precipitation has noticeably less concentrations of $\mathrm{Fe}(\mathrm{III})$ and viscoelastic surfactant. This experiment should be conducted for every viscoelastic 
surfactant separately, since the molecular structure of every surfactant is different and their consequently their reaction with iron.

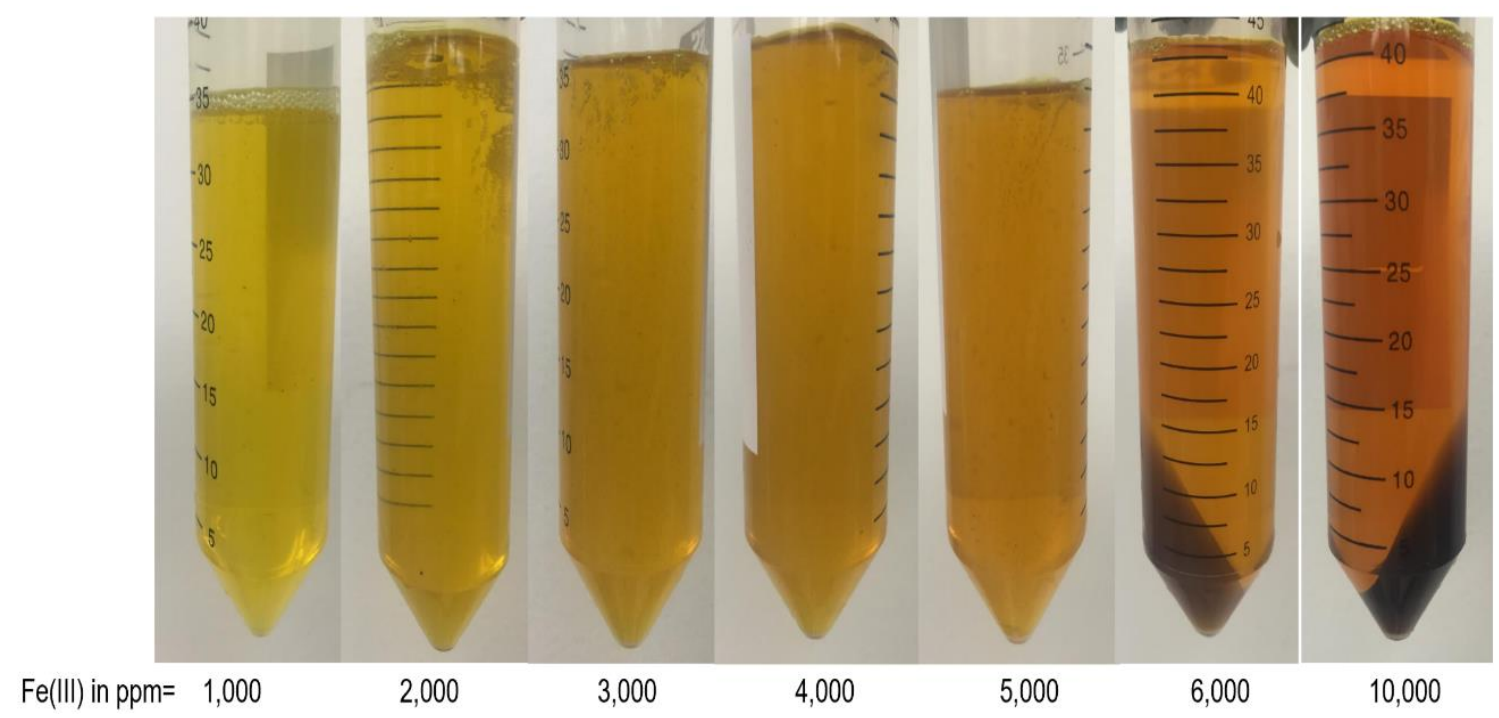

Fig. 4.1. 5 vol\% VES solution with $20 \mathrm{wt} \% \mathrm{HCl}$ with different $\mathrm{Fe}(\mathrm{III})$ concentrations $(1,000-10,000 \mathrm{ppm})$ at $75^{\circ} \mathrm{F}$. When iron (III) concentration was greater than 6,000 , a brown precipitate was observed.

The interaction of Fe(III) and viscoelastic surfactants in VES-based solutions is a well-known phenomenon that mostly depends on head group structure of VES and the acid concentration. As Fig. 4.2 illustrates, adding different concentrations of Fe(III), (1,000-10,000 ppm), to $15 \mathrm{wt} \%$ of $\mathrm{HCl}$ solution, did not cause any phase separation. 


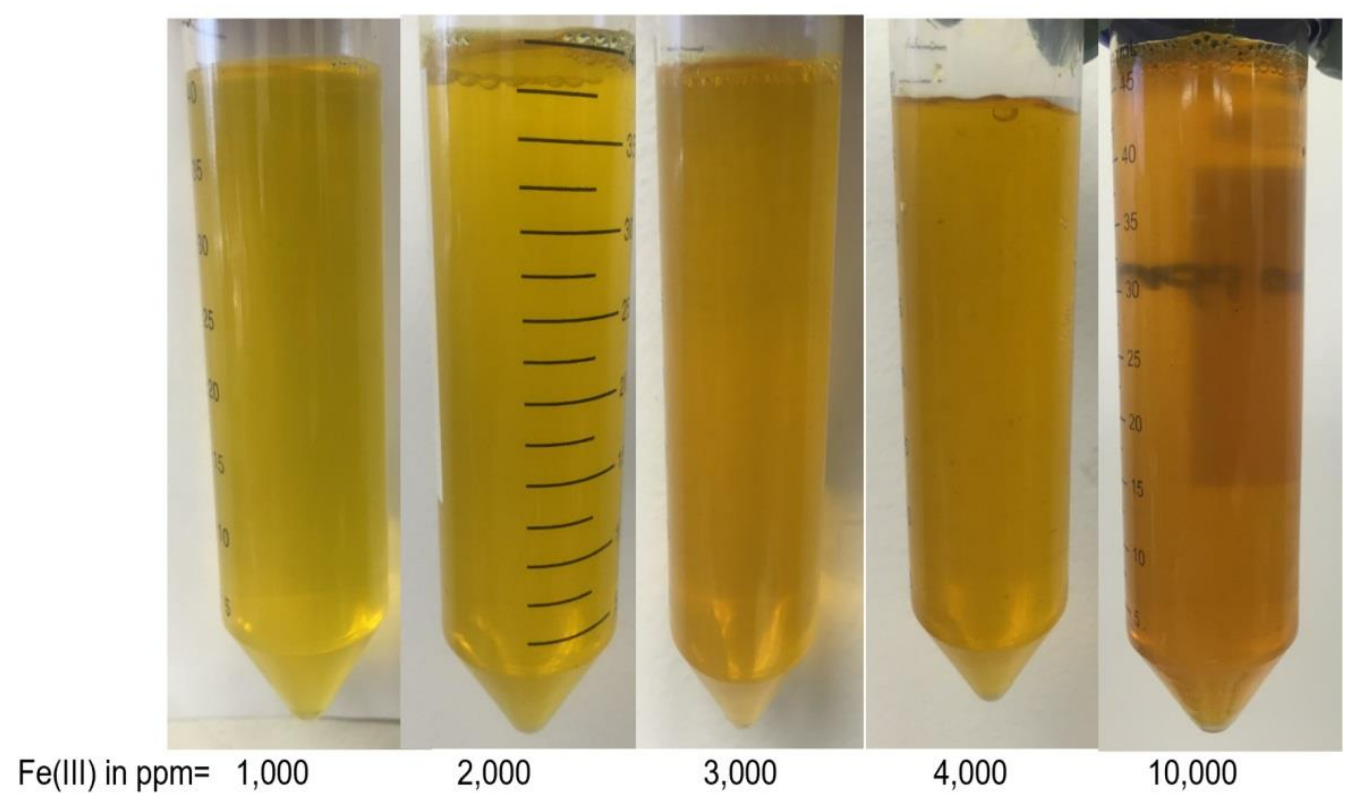

Fig. 4.2. 5 vol\% VES solution with $15 \mathrm{wt} \% \mathrm{HCl}$ with $\mathrm{Fe}(\mathrm{III})$ concentrations (1,000-10,000 ppm) at $75^{\circ} \mathrm{F}$.

In the next part of this study, the effect of Fe(III) on the apparent viscosity of the spent VES-based solutions was investigated. The samples shown in Fig. 4.3 were neutralized by $\mathrm{CaCO}_{3}$ and their apparent viscosity was measured at 350 psi and the temperature range of $80-400^{\circ} \mathrm{F}$. Moreover, Fig. 4.3 shows that for solutions with $\mathrm{Fe}(\mathrm{III})$ concentration lower than $6,000 \mathrm{ppm}$, the apparent viscosity increases as the iron concentration increases in the temperature range of $80-150^{\circ} \mathrm{F}$. It can be explained by molecular packing number of the VES; adding salt (Fe(III)) screens electrostatic interhead group repulsion and thereby reduces the $\mathrm{a}_{0}$ and increases the packing number and will transfer the micelles to the more favorable shape (rodlike). Meanwhile, the maximum apparent viscosity (first peak) of the VES-based solution decreased as the iron concentration increased in the temperature range of $150-250^{\circ} \mathrm{F}$. 
Despite the descending trend, the apparent viscosity of the VES-based acid remained above $150 \mathrm{cp}$ in the presence of 5,000 ppm and lower Fe(III) concentration. For $\mathrm{Fe}(\mathrm{III})$ concentration of $6,000 \mathrm{ppm}$, the apparent viscosity was near one at all temperatures. This result confirms the earlier observation of the brown precipitation as the result of addition of $6,000 \mathrm{ppm}$ iron to the VES-based live acid solution. The brown precipitation consists of $\mathrm{Fe}(\mathrm{III})$ interacting with VES and filtering it out of the solution, causing the spent solution to lose its viscosity. 


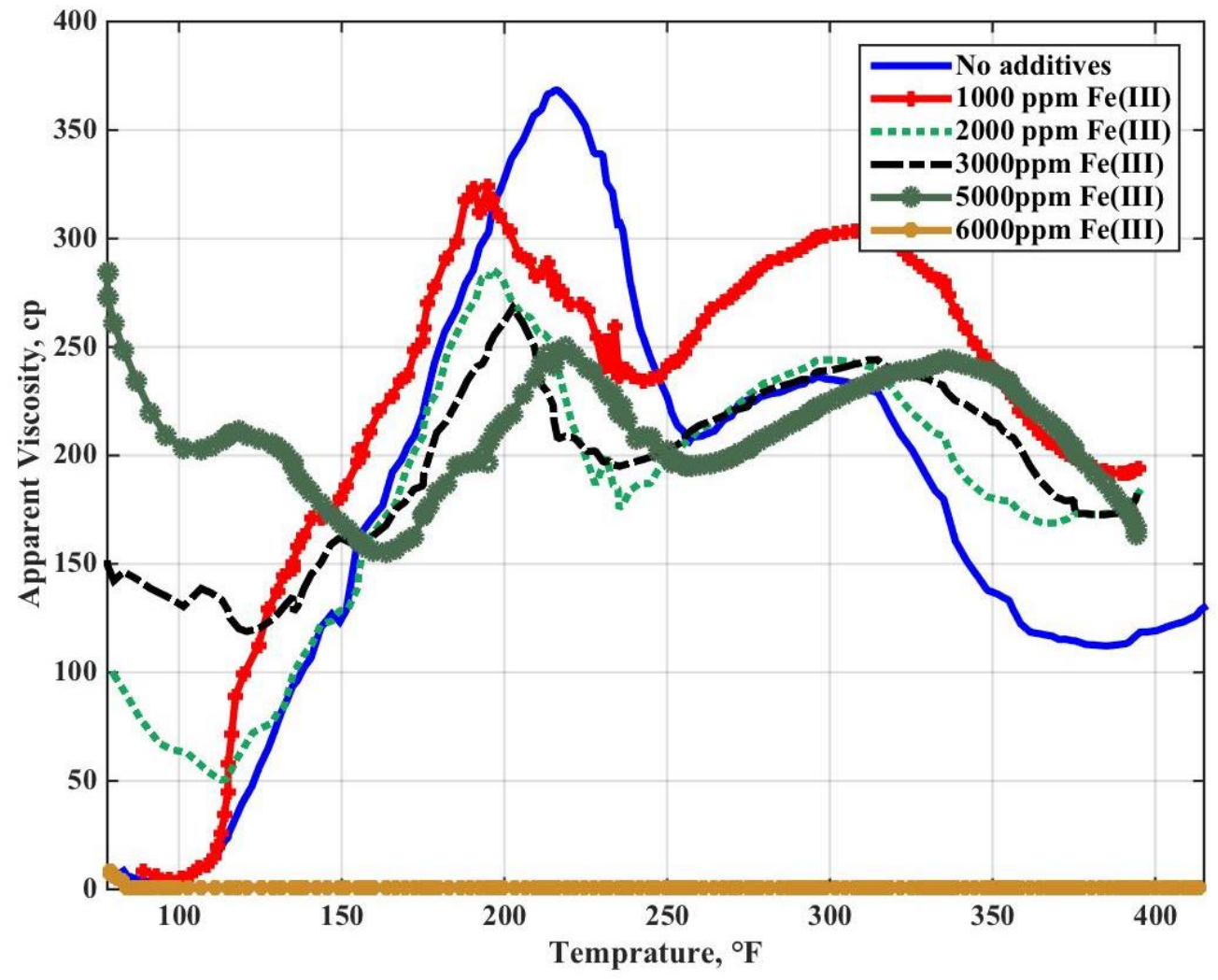

Fig. 4.3. Effect of Fe(III) concentrations on the apparent viscosity of spent $20 \mathrm{wt} \% \mathrm{HCl}$ and $5 \mathrm{vol} \%$ viscoelastic surfactant at $350 \mathrm{psi}$ and a shear rate of $100 \mathrm{~s}^{-1}$. 


\section{CHAPTER V}

\section{EFFECT OF DIFFERENT CHELATING AGENTS ON THE}

\section{APPARENT VISCOSITY OF THE SPENT VES-BASED ACID}

\subsection{Sample preparation}

\subsubsection{Thermal stability sample}

The mixture of the VES and live $20 \mathrm{wt} \%$ acid was prepared for the see-through cell.

1. $54.7 \mathrm{~cm}^{3}$ of $36.5 \% \mathrm{HCl}$ was separated and transferred to a beaker.

2. 2 vol\% corrosion inhibitor A-5300 was added to the solution.

3. $0.107 \mathrm{~mol} / \mathrm{L}$ GLDA and HEDTA was added to the solution

4. Enough calculated deionized (DI) water was added to $\mathrm{HCl}$ to prepare a 100 $\mathrm{cm}^{3}$ of $20 \mathrm{wt} \% \mathrm{HCl}$.

5. $5 \mathrm{~cm}^{3}$ of the VES was added drop by drop to the vortex of the mechanical agitator while it was mixing.

The maximum amount of chelating agents used in the next step was chosen to be added to the solution.

\subsubsection{Spent VES-based acid preparation with different chelating agents}

Simulated spent acid was prepared with $\mathrm{CaCl}_{2} \cdot 2 \mathrm{H}_{2} \mathrm{O}$ and DI water, then different amounts of chelating agents $(0.010,0.053$, and $0.107 \mathrm{~mol} / \mathrm{L})$ were added to the simulated acid. Finally, the VES was added to the solution gradually, and for maintaining the $\mathrm{pH}$ value at 4.5 , a few drops of $\mathrm{HCl}$ were added to the solution. Then, $52 \mathrm{ml}$ of the solution 
was added to the viscometer cup, the apparent viscosity was measured under $350 \mathrm{psi}$ and a shear rate of $100 \mathrm{~s}^{-1}$. The experiments were conducted over a temperature range of 80 to $400^{\circ} \mathrm{F}$.

\subsection{Results and discussions}

\subsubsection{Thermal stability study}

To determine the compatibility of these chelating agents with the viscoelastic surfactant used in this study we conducted a thermal stability test illustrated in Figs. 5.1 and 5.2. 


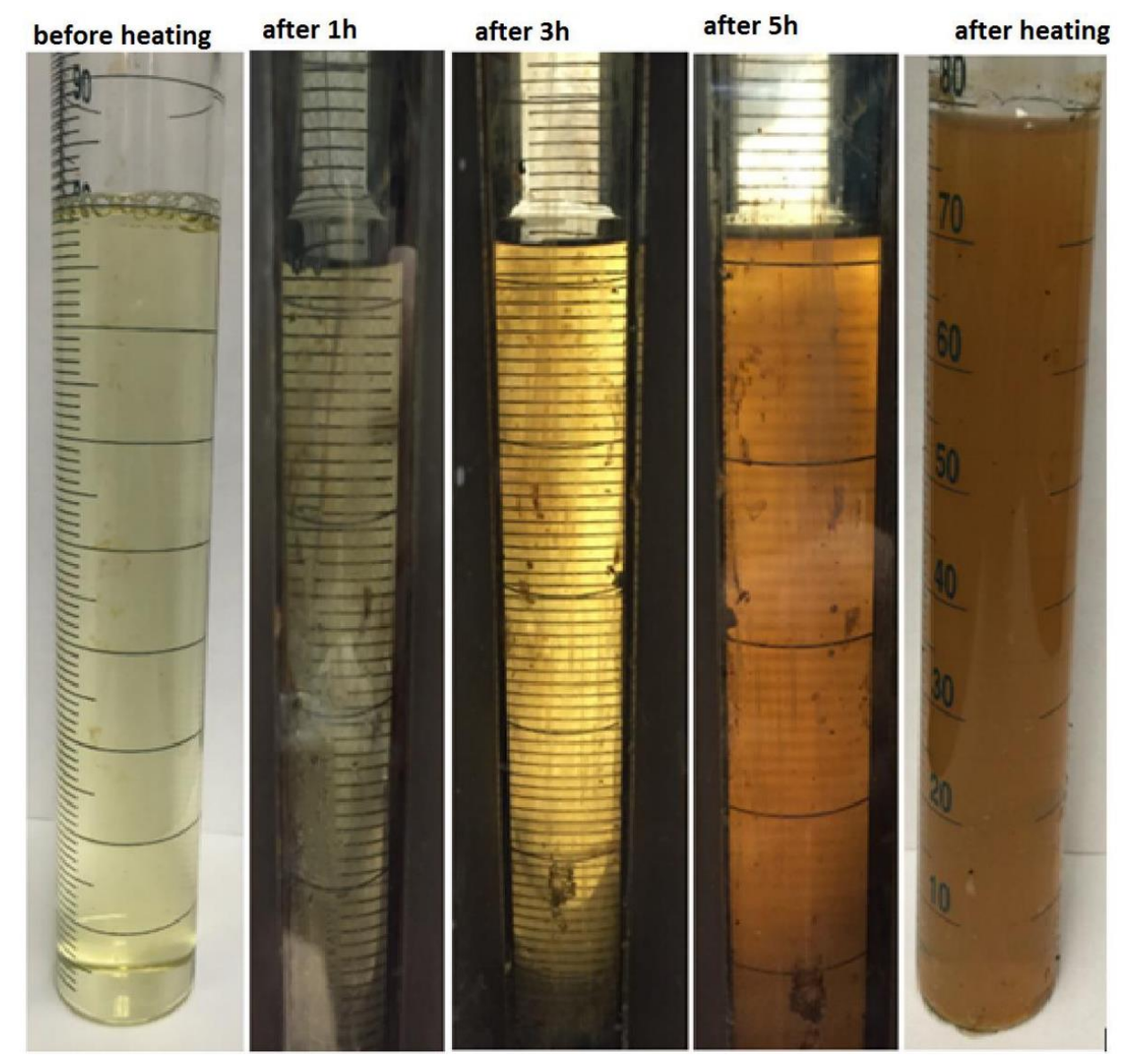

Fig. 5.1. Thermal stability of 5 vol $\%$ VES, 2 vol\% corrosion inhibitor, and $0.107 \mathrm{~mol} / \mathrm{L}$ GLDA, and $20 \mathrm{wt} \% \mathrm{HCl}$ at $200^{\circ} \mathrm{F}$ and 400 psi for 6 hours. 


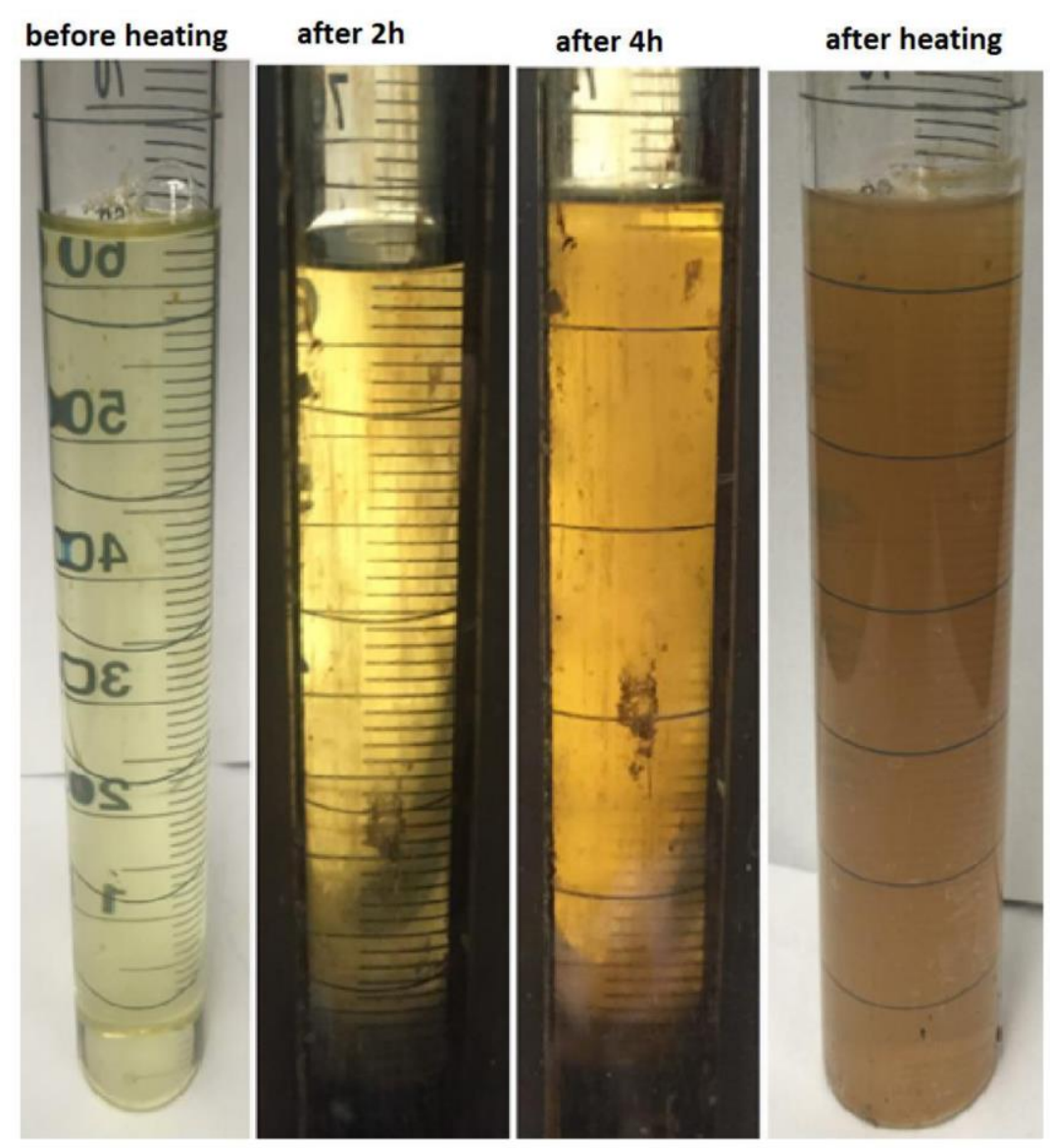

Fig. 5.2. Thermal stability of 5 vol\% VES, 2 vol\% corrosion inhibitor, and $0.107 \mathrm{~mol} / \mathrm{L}$ HEDTA, and $20 \mathrm{wt} \% \mathrm{HCl}$ at $200^{\circ} \mathrm{F}$ and 400 psi for 6 hours.

The thermal stability result confirms the chemical compatibility of the viscoelastic surfactant and the highest concentration of the GLDA and HEDTA used in this study. It also demonstrates a high thermal stability for the VES containing other additives. No precipitation or phase separation was observed during the 6-hour heating process. The color change is due to the corrosion inhibitor. Addition of corrosion inhibitor was due to viscosity measurements in next step, while the viscosity of the live acids was measured with the HP/HT viscometer, corrosion inhibitor is always recommended to protect the 
equipment. The 6-hour long experiment is designed to resemble the average acidizing treatment duration of the vertical wells. The viscosity measurement conducted on the solutions before and after heating to ensure that the VES maintains its viscosity after heating. (Figs 5.3 and 5.4)

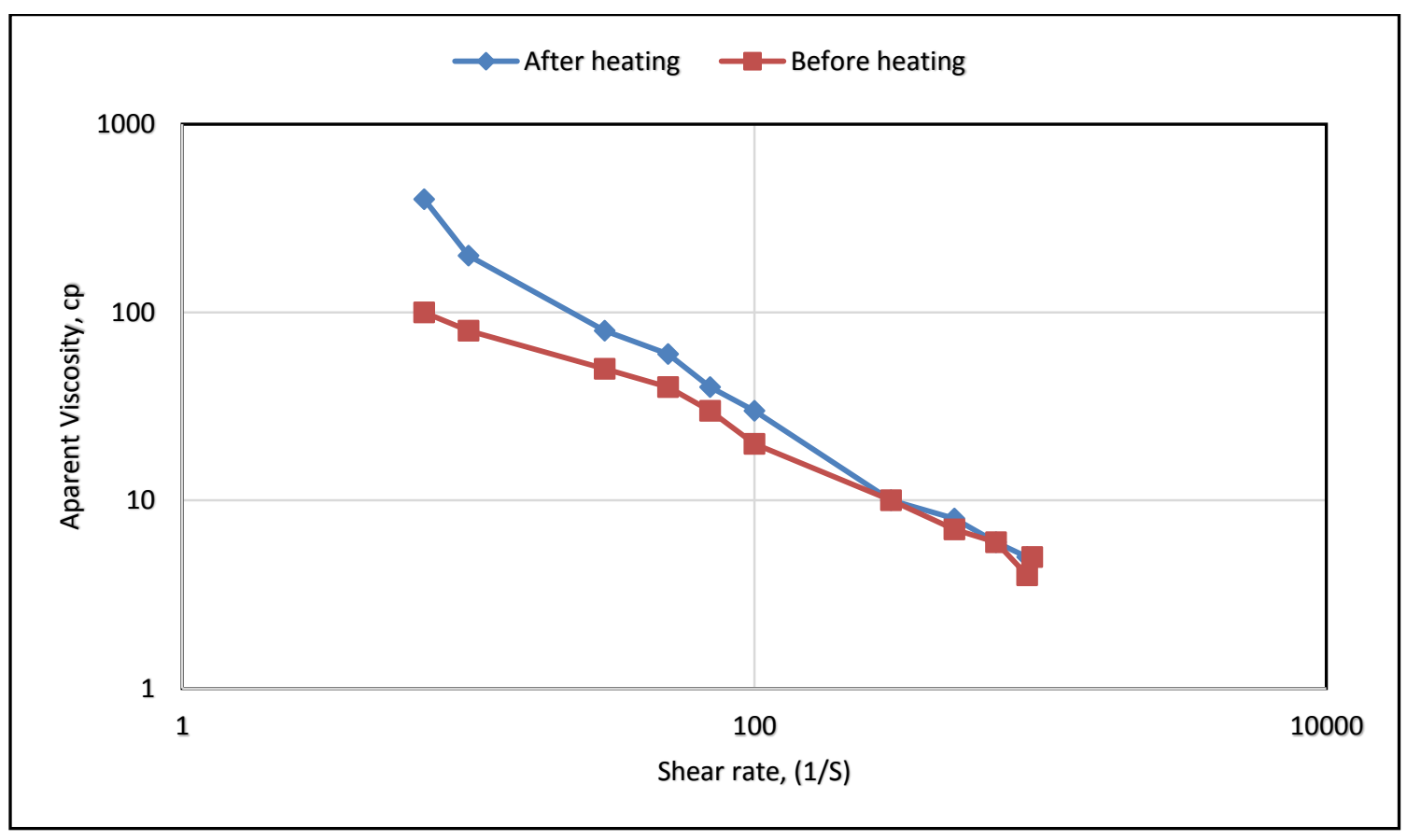

Fig. 5.3. Viscosity versus shear rate of the VES solution (5 vol\% VES, 2 vol\% corrosion inhibitor, $0.107 \mathrm{~mol} / \mathrm{L}$ GLDA and $20 \mathrm{wt} \% \mathrm{HCl}$ ) at $77^{\circ} \mathrm{F}$ and $300 \mathrm{psi}$ before and after heating. 


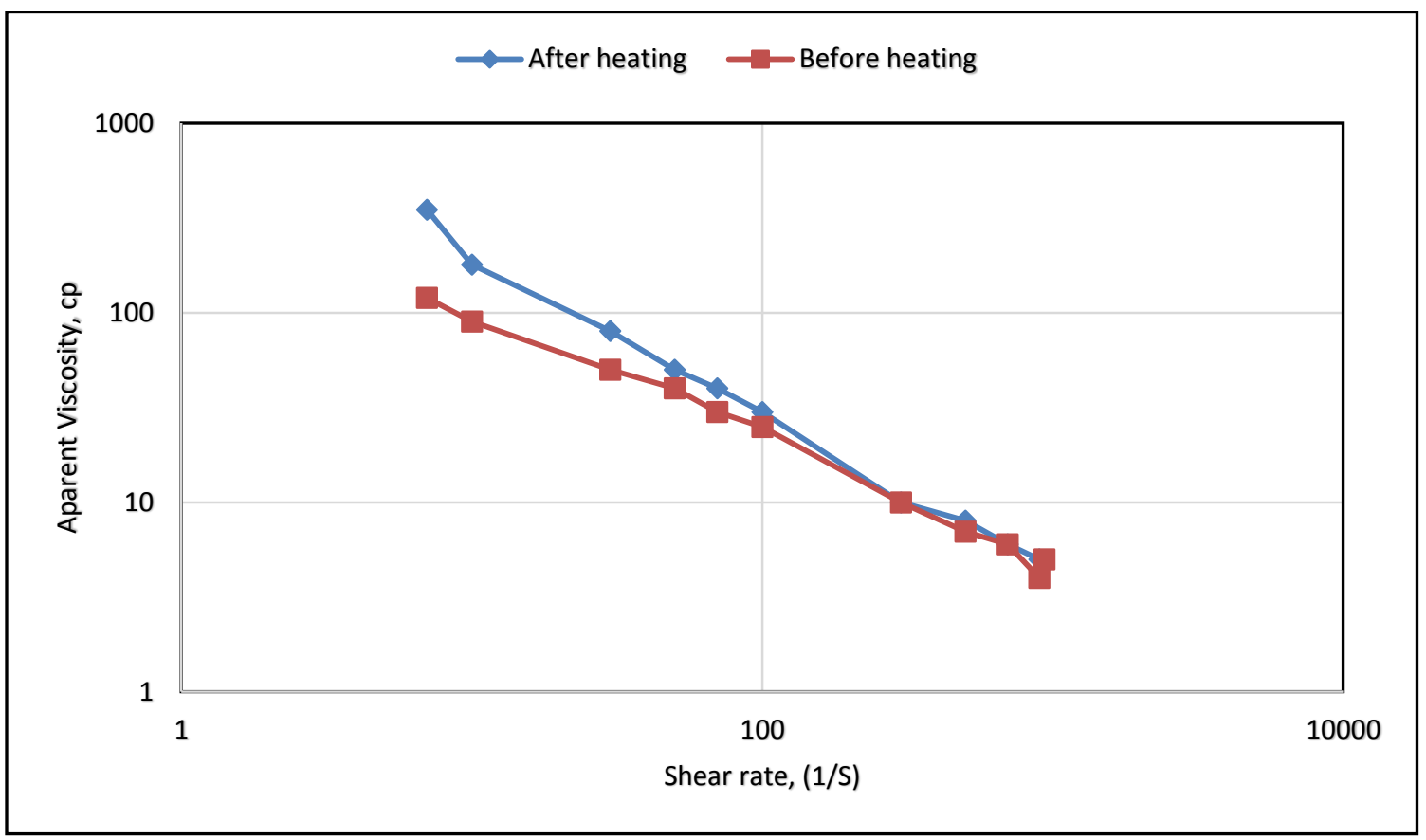

Fig. 5.4. Viscosity versus shear rate of the VES solution (5 vol\% VES, 2 vol\% corrosion inhibitor, $0.107 \mathrm{~mol} / \mathrm{L} \mathrm{HEDTA}$, and $20 \mathrm{wt} \% \mathrm{HCl}$ ) at $77^{\circ} \mathrm{F}$ and 300 psi before and after heating.

Both solutions with GLDA and HEDTA illustrated high viscosity after 6-hours of heating to $200^{\circ} \mathrm{F}$. Therefore, the viscoelastic is compatible with both chelating agents and also have high thermal stability.

\subsubsection{Rheological study}

Different amounts of HEDTA and GLDA were added to the solution (0.010, 0.053, and $0.107 \mathrm{~mol} / \mathrm{L})$. These amounts were respectively calculated from the $1: 1$ molar ratio of chelating agents to iron concentrations of 1,000 ppm, 3,000 ppm, and 6,000 ppm. Figs. 5.5 and 5.6 show that addition of both chelating agents shifted the first peak of the apparent viscosity to lower temperatures; the same trend was observed by Li et al. (2011) with the 
addition of EDTA, GLDA, and HEIDA as (ICA) to the VES based solutions. However, the viscoelastic surfactant used in that study is the amidoamine oxide surfactant which has the different head group and structure that affects the apparent viscosity of the VES-based solution. The apparent viscosity of the aforementioned viscoelastic surfactants showed only one peak and lower temperature tolerance $\left(180^{\circ} \mathrm{F}\right)$ compared to the VES-based solution present in this study; therefore, shifting that was caused by the addition of chelating agents narrowed the temperature ranges even more.

On the other hand, the VES used in this study kept its viscosity properties until $400^{\circ} \mathrm{F}$, and although the first peak of the apparent viscosity reduced by increasing the concentration of chelating agents, the second peak remained high and chelating agents did not narrow the temperature range use of the spent VES-based solutions. Gurluk et al. (2013) stated that VES micelles interaction is stronger in divalent salts than monovalent salts. They conducted an experiment, measuring the viscosity of the VES solution with constant amount of $\mathrm{CaBr}_{2}$ and different concentrations of $\mathrm{MgO}$. The results showed almost constant apparent viscosity with the increase of $\mathrm{MgO}$ concentration, while the combination of the $\mathrm{CaBr}_{2}$ and the lowest concentrations of $\mathrm{MgO}$ showing a significant amount of increase in the viscosity of the solution.

As Fig. 2.2 also shows, GLDA and HEDTA both contain sodium salt, and when adding $0.017 \mathrm{~mol} / \mathrm{L}$ GLDA or HEDTA (lowest amount) the apparent viscosity increased, but when the concentration of chelating agent is increased $(0.053$ and $0.107 \mathrm{~mol} / \mathrm{L})$ mostly the first peak of the apparent viscosity decreased. While, the amount of $\mathrm{Na}^{+1}$ salt is increased and due to formation of chelating agents complex with the $\mathrm{Ca}^{+2}$ salt less amount 
of $\mathrm{Ca}^{+2}$ salt is left for interacting with VES head group. Therefore, the apparent viscosity commenced to decrease at higher concentrations of both chelating agents.

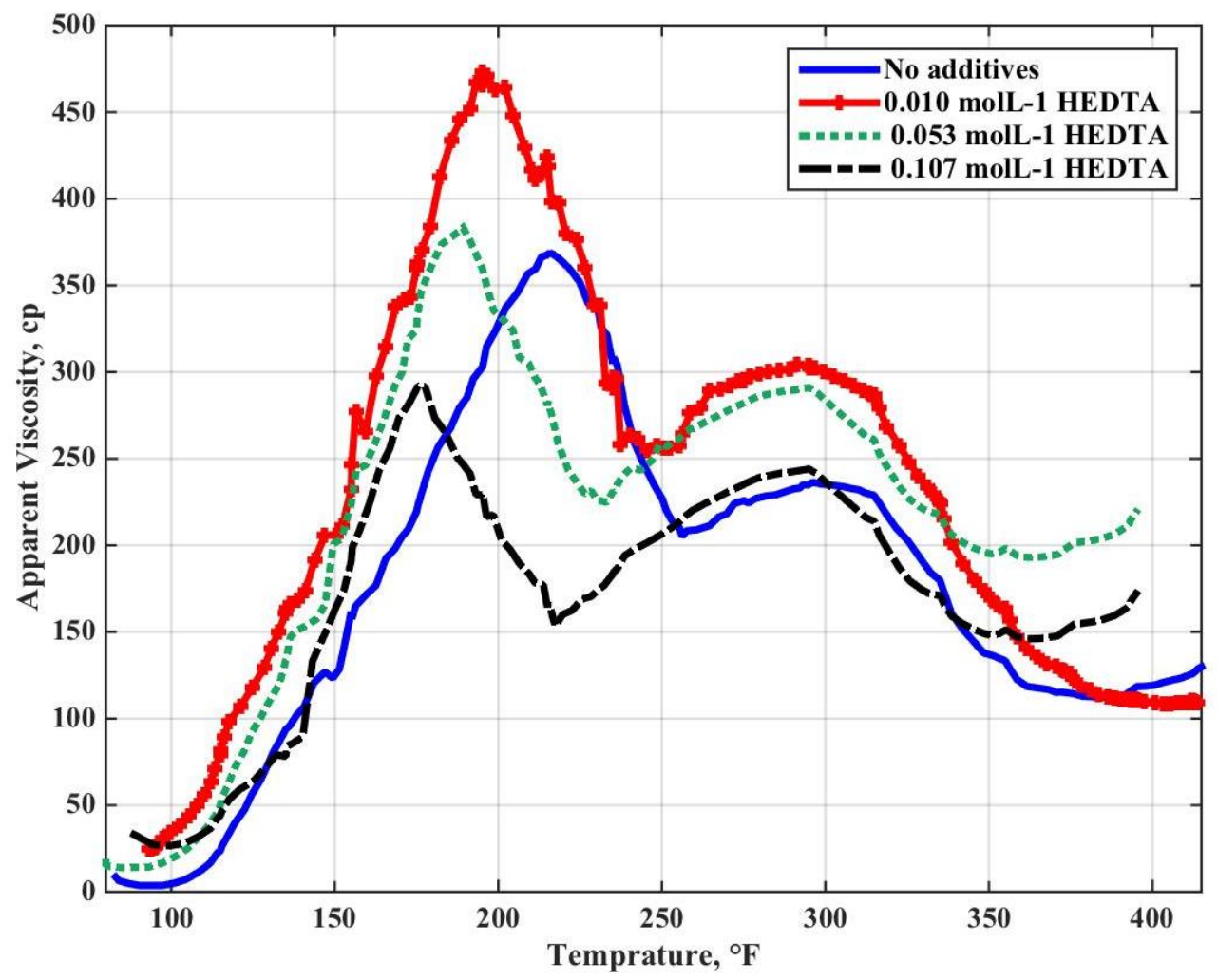

Fig. 5.5. Effect of HEDTA concentration on the apparent viscosity of the spent $20 \mathrm{wt} \%$ $\mathrm{HCl}$ and $5 \mathrm{vol} \%$ VES at $350 \mathrm{psi}$ and a shear rate of $100 \mathrm{~s}^{-1}$. 


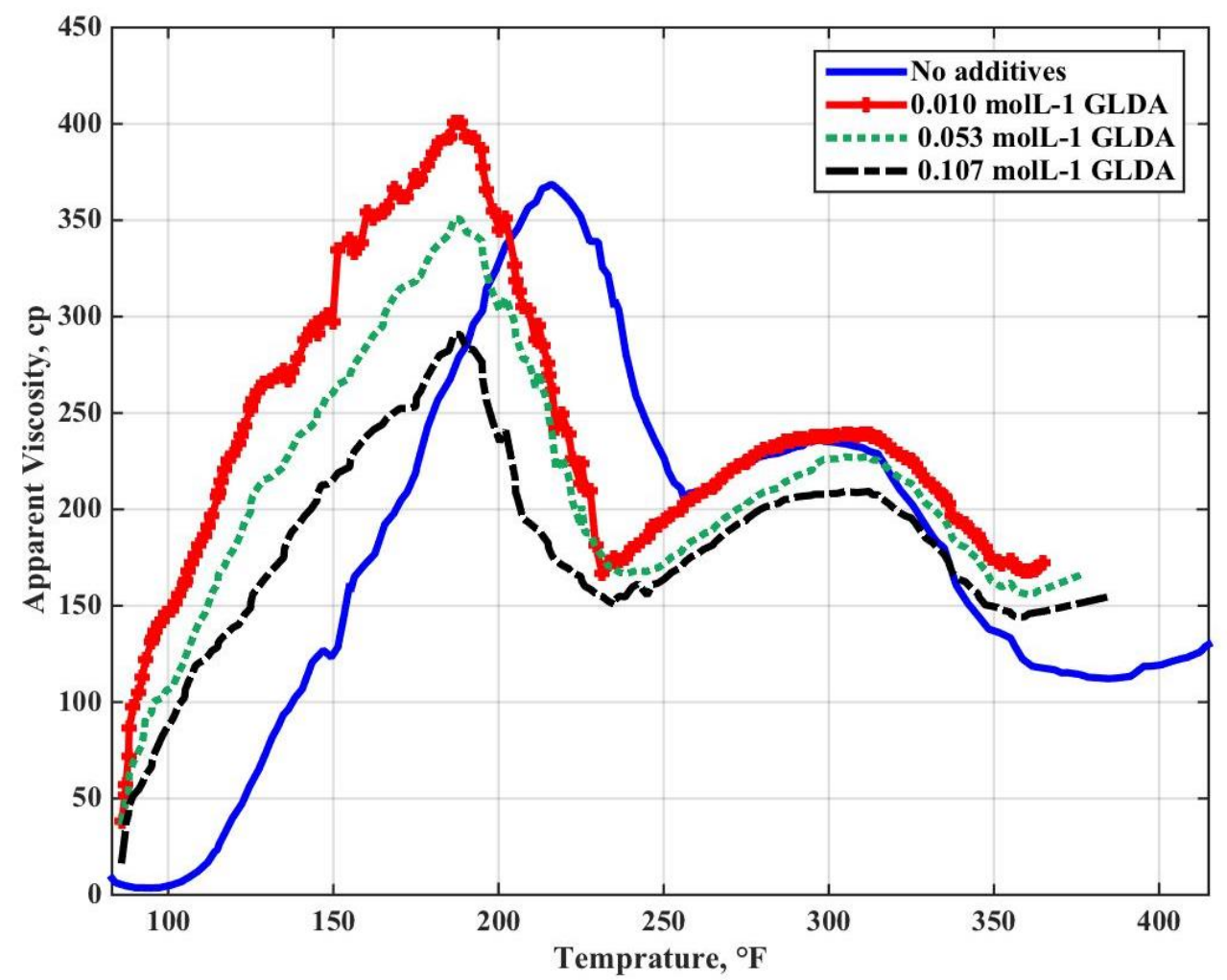

Fig. 5.6. Effect of GLDA concentration on the apparent viscosity of the spent $20 \mathrm{wt} \% \mathrm{HCl}$ and $5 \mathrm{vol} \%$ VES at $350 \mathrm{psi}$ and a shear rate of $100 \mathrm{~s}^{-1}$. 
CHAPTER VI

EFFECT OF CHELATING AGENT ADDITION TO THE SPENT

VES-BASED ACID SOLUTION WITH DIFFERENT CON-

CENTRATIONS OF IRON (III) ON THE APPARENT VISCOSITY

OF THE SPENT ACID

\subsection{Sample preparation}

6.1.1. Spent VES-based acid preparation with Ferric Chloride and 1 to 1 molar chelating agent

1. $54.7 \mathrm{~cm}^{3}$ of $36.5 \mathrm{wt} \% \mathrm{HCl}$ was separated and transferred to a beaker.

2. Chelating agent (1:1 molar to the ferric chloride concentration) was added to the $36.5 \mathrm{wt} \% \mathrm{HCl}$.

3. Calculated amount of DI water added to reach $20 \mathrm{wt} \% \mathrm{HCl}$.

4. VES was added drop by drop to the vortex of the mechanical agitator while it was mixing.

5. Finally, before neutralizing the acid, different amounts of ferric chloride (1,000-6,000 ppm) was added to the solution.

\subsection{Results and discussions}

$\mathrm{Fe}(\mathrm{III})$ concentrations below 6,000 ppm only reduced the first peak of the apparent viscosity of the VES, but at $6,000 \mathrm{ppm}$ and higher concentrations, Fe(III) interacted with 
the viscoelastic surfactant, and the spent VES-based solution entirely lost its viscosity property. High concentrations of chelating agents $(0.053$ and $0.107 \mathrm{~mol} / \mathrm{L})$ also caused the first peak of the apparent viscosity to reduce. Therefore, this work further investigated the effect of both additives simultaneously on the apparent viscosity of the viscoelastic surfactants. The experimental results indicated that the negative effect of chelating agents was not superimposed on the negative effect of $\mathrm{Fe}(\mathrm{III})$ and reduced the apparent viscosity even further.

On the other hand, Figs. 6.1 and 6.2 display that adding 1:1 HEDTA and GLDA to the $6,000 \mathrm{ppm} \mathrm{Fe}$ (III) impressively assisted the $6,000 \mathrm{ppm}$ iron (III) solution to increase its apparent viscosity from almost $1 \mathrm{cp}$ to the maximum viscosity of $270 \mathrm{cp}$ at $200^{\circ} \mathrm{F}$. Also, comparing the apparent viscosity of spent VES-based solution with $0.107 \mathrm{~mol} / \mathrm{L}$ GLDA or HEDTA to the same spent VES-based solution with addition of the Fe(III) concentration of $6,000 \mathrm{ppm}$, showed that apparent viscosity of the solution was not significantly affected by iron (III). The apparent viscosity of spent condition was measured for lower concentrations of $\mathrm{Fe}(\mathrm{III})(1,000-5,000 \mathrm{ppm})$ which did not interact with the live VES, and as observed in the previous section that the apparent viscosity of the spent solutions increased in lower temperatures $\left(150^{\circ} \mathrm{F}\right)$ as the $\mathrm{Fe}(\mathrm{III})$ concentration increased. High viscosity of the spent VES-based solution in low temperature caused by iron contamination from the tanks in the field can cause pumping complications.

Fig. 6.3 compares the apparent viscosity of the two spent VES-based solutions, (i) only contains 5,000 ppm Fe(III), (ii) combination of 5,000 ppm Fe(III) and 1:1 molar ratio of chelating agents (HEDTA and GLDA). The results revealed that chelating agents 
reduced the apparent viscosity of the spent VES-based solution containing iron at low temperatures $\left(80-140^{\circ} \mathrm{F}\right)$. Chelating agents complex with $\mathrm{Fe}(\mathrm{III})$ have higher association constant compared to the bond between Fe(III) and the VES head group. Therefore, chelating agents are demonstrated to assist the VES rheological properties.

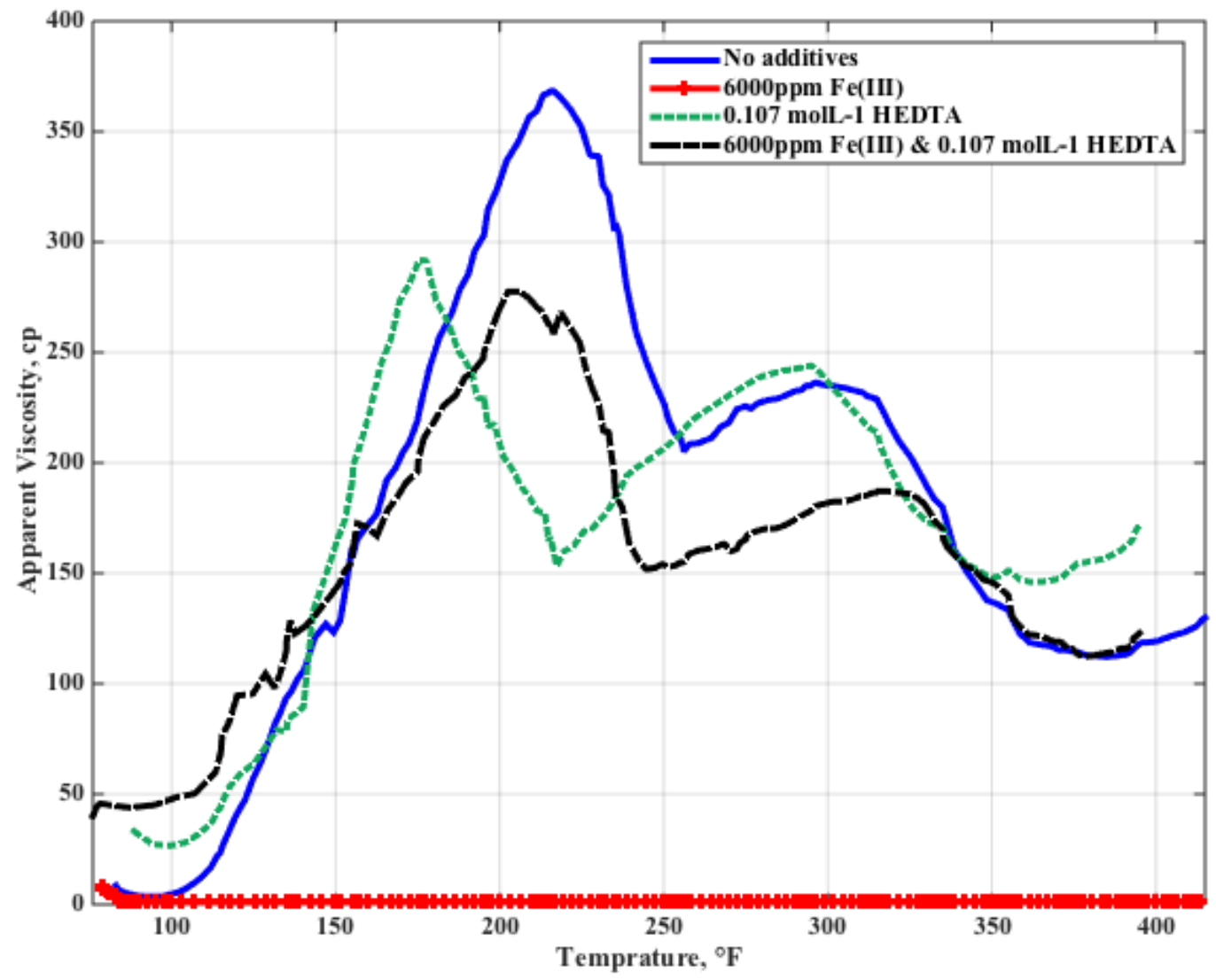

Fig. 6.1. Effect of HEDTA (1:1 molar to Fe(III)) on the apparent viscosity of the spent 20 wt $\% \mathrm{HCl}$ and $5 \mathrm{vol} \% \mathrm{VES}$ with $6,000 \mathrm{ppm} \mathrm{Fe}(\mathrm{III})$ at $350 \mathrm{psi}$ and a shear rate of $100 \mathrm{~s}^{-1}$. 


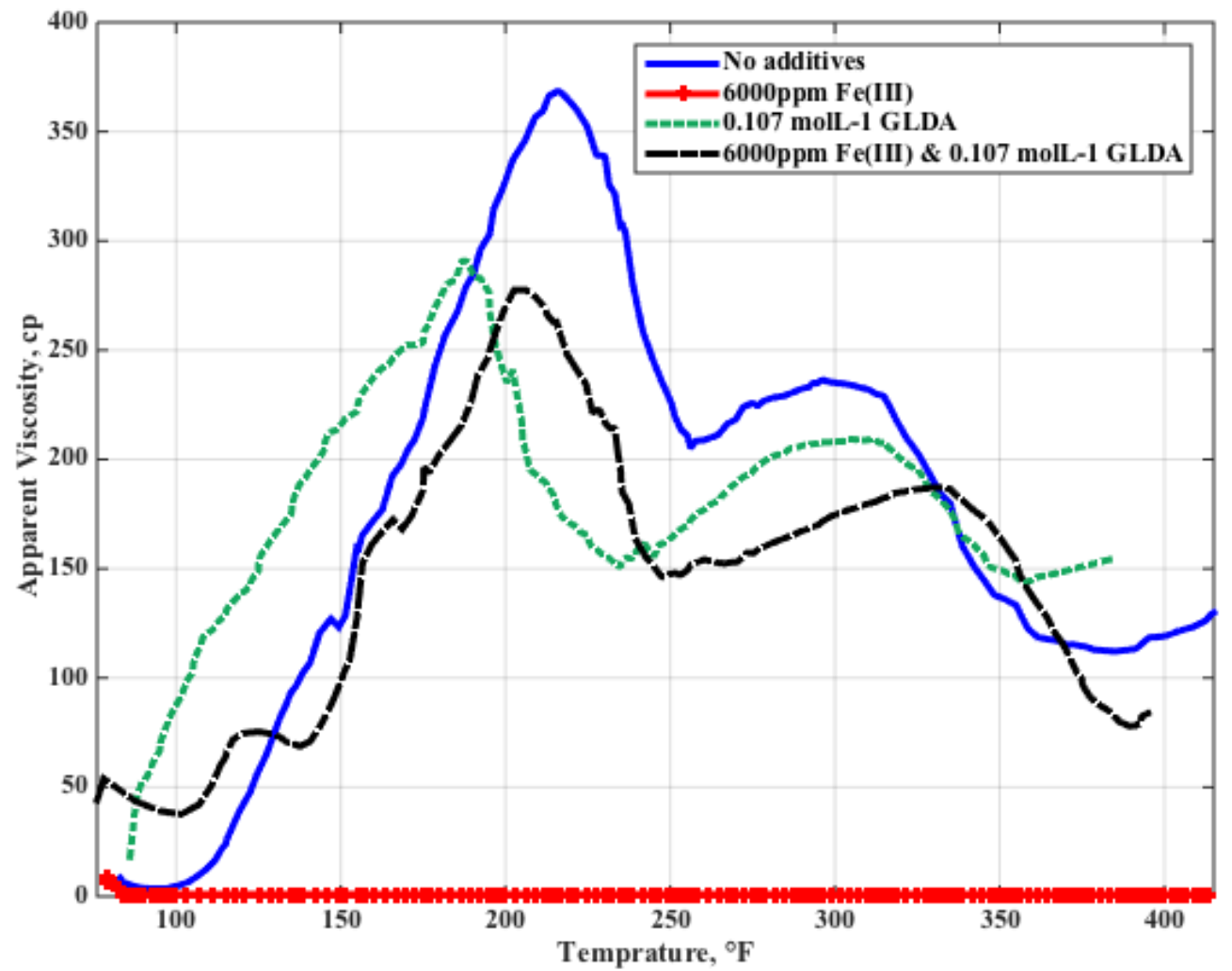

Fig. 6.2. Effect of GLDA (1:1 molar to Fe(III)) on the apparent viscosity of the spent 20 $\mathrm{wt} \% \mathrm{HCl}$ and $5 \mathrm{vol} \% \mathrm{VES}$ with 6,000 ppm Fe(III) at $350 \mathrm{psi}$ and a shear rate of $100 \mathrm{~s}^{-1}$. 


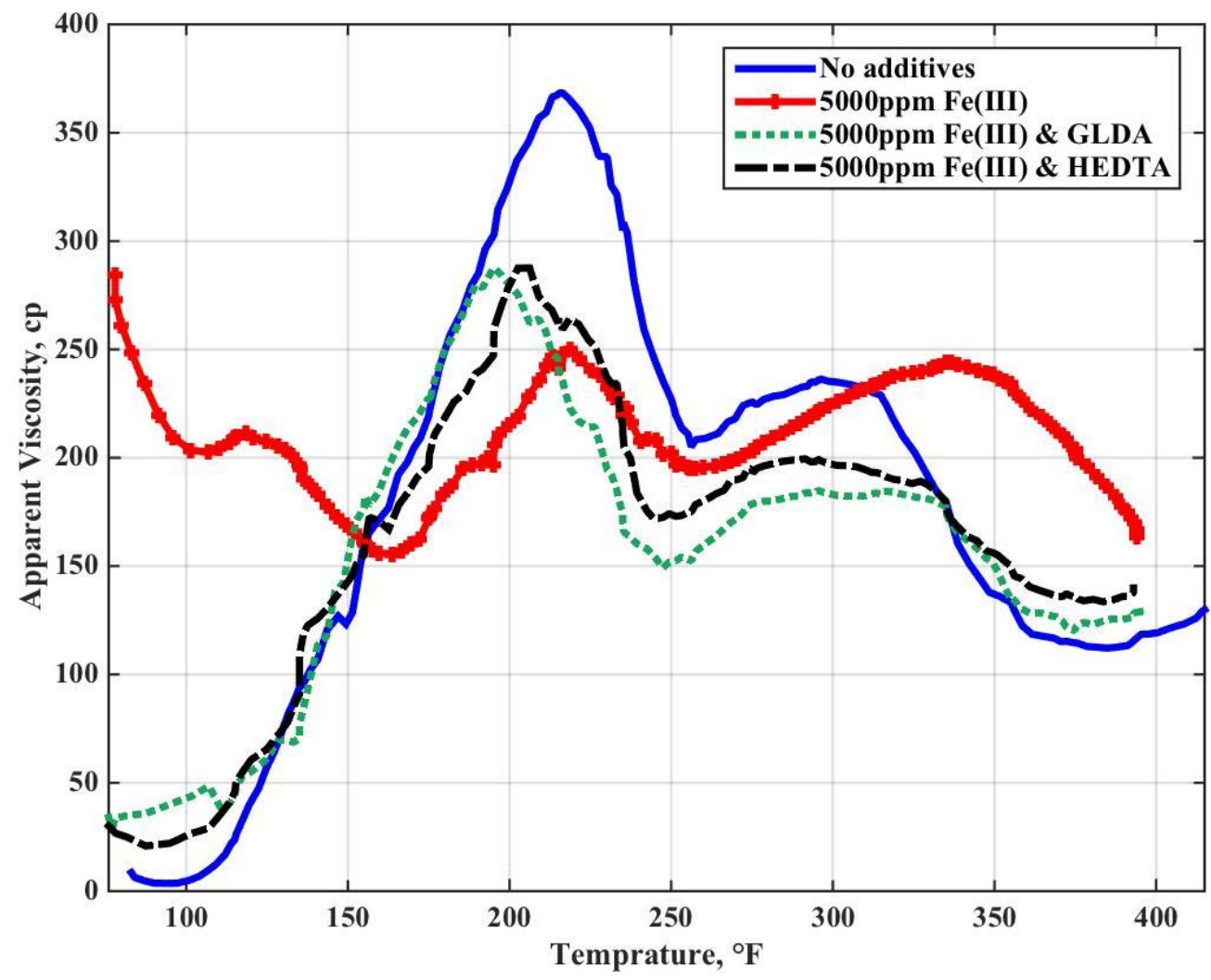

Fig. 6.3. Effect of GLDA and HEDTA (1:1 molar ratio to Fe(III)) on the apparent viscosity of the spent $20 \mathrm{wt} \% \mathrm{HCl}$ VES with 5,000 ppm Fe(III) at $350 \mathrm{psi}$ and a shear rate of 100 $\mathrm{s}^{-1}$. 


\section{CHAPTER VII}

\section{CONCLUSIONS AND RECOMMENDATIONS}

\subsection{Conclusions}

In this study, a new viscoelastic surfactant for acid diversion in carbonate acidizing was investigated and also the interaction among $\mathrm{Fe}(\mathrm{III})$ and two chelating agents (HEDTA, GLDA) with the VES in spent conditions was studied. The following conclusions could be drawn:

1. The apparent viscosity of spent VES-based acids which obtained by three different methods of preparation, indicated similar paths versus temperature (similar viscosity in same temperature), allowing us to also compare the outcome of these methods while containing additives.

2. The new viscoelastic surfactant with a strong anionic head group has high thermal stability in spent conditions, maintaining a minimum apparent viscosity of $150 \mathrm{cp}$ in the temperature range of $80-150^{\circ} \mathrm{F}$.

3. The live VES-based acid was compatible with Fe(III) concentrations lower than 6,000 ppm. At higher concentrations of Fe(III) the VES interacted with the iron and precipitated.

4. In spent conditions, the apparent viscosity of the VES solutions is affected by the $\mathrm{Fe}(\mathrm{III})$ ions. As the Fe(III) concentration increases, (up to 5,000 ppm) the apparent viscosity increases in temperatures lower than $150^{\circ} \mathrm{F}$. At higher temperatures, the maximum apparent viscosities decreased as we increased the iron concentration 
but still remained impressively high $\left(150 \mathrm{cp}\right.$ at $\left.400^{\circ} \mathrm{F}\right)$.

5. Chelating agents HEDTA and GLDA both reduced the first peak of the apparent viscosity of the spent VES solutions as we increased their concentration. The second peak of the apparent viscosity versus temperature was reduced less compared to the first peak. The VES solution viscosity remained above $100 \mathrm{cp}$ with $0.107 \mathrm{~mol} / \mathrm{L}$ HEDTA and $140 \mathrm{cp}$ with $0.107 \mathrm{~mol} / \mathrm{L}$ GLDA.

6. The negative impact of the chelating agents on the apparent viscosity did not superimpose on the negative effect of $\mathrm{Fe}(\mathrm{III})$ on the apparent viscosity. Chelating agents rebuilt the viscosity of the VES-based solution with 6,000 ppm Fe(III), and, for the 5,000 ppm iron (III) solution, they reduced the apparent viscosity at lower temperatures $\left(150^{\circ} \mathrm{F}\right)$ and increased the viscosity in the temperature range of 150 $250{ }^{\circ} \mathrm{F}$. Therefore, chelating agents are recommended to be used with the VESbased solutions.

This work introduces a new VES-based acid with high temperature tolerance and compatibility with additives. The rheology experiments show the effect of the Fe(III) contamination on the viscosity of the VES-based acid solutions in spent conditions. To avoid this effect ICA (GLDA and HEDTA) were used.

\subsection{Recommendations}

Based on the outcome of this study we recommend flowing the below procedure while conducting matrix acidizing with viscoelastic-surfactant-based acids. 
1. Thermal stability of the viscoelastic surfactant should be in the temperature range of the treating formation.

2. The concentration of $\mathrm{Fe}(\mathrm{III})$ contamination present in the treatment should be measured in the preflush.

3. Obtain the maximum concentration of Fe(III) that your VES can tolerate in live acid.

4. According to the above results consider using a chelating agent to prevent the interaction of the Fe(III) with VES. Also in some cases changing the VES type will be a more economical solution.

5. Rheological study on the final VES-based solution (after the addition of chelating agents or other additives) is highly recommended before the treatment. 


\section{REFERENCES}

Al-Mutawa, M., Al-Anzi, E., Jemmali, M., et al. 2005. Zero-Damaging Stimulation and Diversion Fluid: Field Cases from the Carbonate Formations in North Kuwait. SPE Prod \& Fac 20 (2): 94-105. SPE-80225-PA. http://dx.doi.org/10.2118/80225-PA.

Al-Nakhli, A. R., Nasr-El-Din, H. A., and Al-Baiyat, A. A. 2008. Interactions of Iron and Viscoelastic Surfactants: A New Formation-Damage Mechanism. SPE International Symposium and Exhibition on Formation Damage Control, Lafayette, Louisiana, USA, 13-15 February. SPE-112465-MS. http://dx.doi.org/10.2118/112465-MS.

Begum, Z. A., Rahman, I. M., Sawai, H., et al. 2012. Stability constants of Fe (III) and Cr (III) complexes with dl-2-(2-carboxymethyl) nitrilotriacetic acid (GLDA) and 3hydroxy-2, 2'-iminodisuccinic acid (HIDS) in aqueous solution. Journal of Chemical \& Engineering Data 57 (10): 2723-2732. http://dx.doi.org/10.1021/je3005936.

Bhargava, P., Tu, Y., Zheng, J. X., et al. 2007. Temperature-induced reversible morphological changes of polystyrene-block-poly (ethylene oxide) micelles in solution. Journal of the American Chemical Society 129 (5): 1113-1121. http://dx.doi.org/10.1021/ja0653019.

Cawiezel, K. E., and Dawson, J. C., 2007. Method of Acidizing a Subterranean Formation with Diverting Foam or Fluid. US Patent No. 7303018 B2.

Chang, F., Qu, Q., and Frenier, W. 2001. A Novel Self-Diverting-Acid Developed for Matrix Stimulation of Carbonate Reservoirs. SPE International Symposium on Oilfield Chemistry, Houston, Texas, USA, 13-16 February. SPE-65033-MS. http://dx.doi.org/10.2118/65033-MS.

Crews, J. B., and Huang, T. 2007. Internal Breakers for Viscoelastic-Surfactant Fracturing Fluids. SPE International Symposium on Oilfield Chemistry Conference, Houston, Texas, USA, 28 February-2 March. http://dx.doi.org/10.2118/106216-MS.

De Wolf, C., Bang, E., Bouwman, A., et al. 2014. Evaluation of Environmentally Friendly Chelating Agents for Applications in the Oil and Gas Industry. SPE International Symposium and Exhibition on Formation Damage Control, Lafayette, Louisiana, USA, 26-28 February. SPE-168145-MS. http://dx.doi.org/10.2118/168145-MS.

Dill, W., and Smolarchuk, P. 1988. Iron Control in Fracturing and Acidizing Operations. J Can Pet Technol 27 (3): 75-78. http://dx.doi.org/10.2118/88-03-08. 
Fogang, L. T., Sultan, A. S., and Kamal, M. S. 2016. Comparing the Effects of Breakers on a Long-Tail Sulfobetaine Viscoelastic Surfactant Solution for Well Stimulation. Abu Dhabi International Petroleum Exhibition \& Conference, Abu Dhabi, UAE, 7-10 November. SPE-182915-MS. http://dx.doi.org/10.2118/182915-MS.

Fredd, C., and Fogler, H. 1997. Chelating Agents as Effective Matrix Stimulation Fluids for Carbonate Formations. SPE International Symposium on Oilfield Chemistry, Houston, Texas, USA, 18-21 February. SPE-37212-MS. http://dx.doi.org/10.2118/37212-MS.

Frenier, W., Brady, M., Al-Harthy, S., et al. 2004. Hot Oil and Gas Wells Can Be Stimulated Without Acids. SPE International Symposium and Exhibition on Formation Damage Control, Lafayette, Louisiana, USA, 18-20 February. SPE86522-MS. http://dx.doi.org/10.2118/86522-MS.

Frenier, W., Rainey, M., Wilson, D., et al. 2003. A Biodegradable Chelating Agent is Developed for Stimulation of Oil and Gas Formations. SPE/EPA/DOE Exploration and Production Environmental Conference, San Antonio, Texas, USA, 10-12 March. SPE-80597-MS. http://dx.doi.org/10.2118/80597-MS.

Frenier, W. W., 1986. Solvent for removing iron oxide deposits. US Patent No. 4623399 A.

Frenier, W. W. 2001. Novel Scale Removers are Developed for Dissolving Alkaline Earth Deposits. SPE International Symposium on Oilfield Chemistry, Houston, Texas, USA, 13-16 February. SPE-65027-MS. http://dx.doi.org/10.2118/65027-MS.

Fu, D., and Chang, F., 2005. Compositions and Methods for Treating a Subterranean Formation. US Patent No. 6929070 B2.

Gadberry, J. A., Engel, M. J., Douglas Nowak, J., et al., 2012. Thickened viscoelastic fluids and uses thereof. US Patent No. WO2012160008 A1.

Gougler, P. D. J., Hendrick, J. E., and Coulter, A. W. 1985. Field Investigation Identifies Source and Magnitude of Iron Problems. SPE Production Operations Symposium, Oklahoma City, Oklahoma, USA, 10-12 March. SPE-13812-MS. http://dx.doi.org/10.2118/13812-MS.

Hall, B. E., and Dill, W. R. 1988. Iron Control Additivies for Limestone and Sandstone Acidizing of Sweet and Sour Wells. SPE Formation Damage Control Symposium, Bakersfield, California, USA, 8-9 February. SPE-17157-MS. http://dx.doi.org/10.2118/17157-MS. 
Hanafy, A., Nasr-El-Din, H. A., Rabie, A., et al. 2016. New Viscoelastic Surfactant with Improved Diversion Characteristics for Carbonate Matrix Acidizing Treatments of paper. SPE Western Regional Meeting, Anchorage, Alaska, USA, 23-26 May. SPE-180435-MS. http://dx.doi.org/10.2118/180435-MS.

Heus, M., Lammers, H., Volmer, A., 2013. Process to prepare amino acid-N, N-diacetic acid compounds. US Patent No. 8551312 B2.

Hull, K. L., Sayed, M., and Al-Muntasheri, G. A. 2015. Recent Advances in Viscoelastic Surfactants for Improved Production from Hydrocarbon Reservoirs. SPE J 21 (4): 1,340-1,357. SPE-173776-PA. http://dx.doi.org/10.2118/173776-PA.

Israelachvili, J. N. 1992. Intermolecular and Surface Forces, second edition. London, Academic Press.

Israelachvili, J. N., Mitchell, D. J., and Ninham, B. W. 1976. Theory of Self-Assembly of Hydrocarbon Amphiphiles into Micelles and Bilayers. J. Chem. Soc., Farad. Trans. 2 (72): 1,525-1,567. http://dx.doi.org/10.2118/180435-MS.

Johnson, D. E., Fox, K. B., Burns, L. D., et al. 1988. Carbonate Production Decline Rates Are Reduced Through Improvements in Gelled Acid Technology. SPE Permian Basin Oil and Gas Recovery Conference, Midland, Texas, USA, 10-11 March. SPE-17297-MS. http://dx.doi.org/10.2118/17297-MS.

Kalfayan, L. I., and Martin, A. N. 2009. The Art and Practice of Acid Placement and Diversion: History, Present State and Future. SPE Annual Technical Conference and Exhibition, New Orleans, Louisiana, USA, 4-7 October. SPE-124141-MS. http://dx.doi.org/10.2118/124141-MS.

Karger, B. L., Gant, J. R., Martkopf, A., et al. 1976. Hydrophobic effects in reversedphase liquid chromatography. Journal of Chromatography A 128 (1): 65-78. http://dx.doi.org/10.1016/S0021-9673(00)84032-7.

Kolodynska, D., Jachula, J., and Hubicki, Z. 2009. MGDA as a new biodegradable complexing agent for sorption of heavy metal ions on anion exchanger Lewatit Monoplus M 600. International Symposium on Physico-Chemical Methods of Separation-Ars Separatoria, Kudowa, Zdroj, 14-18 June.

LePage, J. N., De Wolf, C., Bemelaar, J., et al. 2011. An environmentally friendly stimulation fluid for high-temperature applications. SPE J. 16 (1): 104-110. SPE121709-PA. http://dx.doi.org/10.2118/121709-PA.

Li, L., Nasr-El-Din, H. A., and Crews, J. B. 2011. Impact of Organic Acids/Chelating Agents on the Rheological Properties of an Amidoamine-Oxide Surfactant. SPE 
Prod \& Oper 26 (1): 30-40. SPE-121716-PA. http://dx.doi.org/10.2118/121716PA.

Lu, J., Goudarzi, A., Chen, P., et al. 2014. Enhanced oil recovery from high-temperature, high-salinity naturally fractured carbonate reservoirs by surfactant flood. Journal of Petroleum Science and Engineering $\mathbf{1 2 4}$ 122-131. http://dx.doi.org/10.1016/j.petrol.2014.10.016.

Lynn, J. D., and Nasr-El-Din, H. A. 2001. A Core Based Comparison of the Reaction Characteristics of Emulsified and In-Situ Gelled Acids in Low Permeability, High Temperature, Gas Bearing Carbonates. SPE International Symposium on Oilfield Chemistry, Houston, Texas, USA, 13-16 February. SPE-65386-MS. http://dx.doi.org/10.2118/65386-MS.

Malik, M. A., Hashim, M. A., Nabi, F., et al. 2011. Anti-corrosion ability of surfactants: a review. Int. J. Electrochem. Sci. 6 (6): 1,927-1,948.

Martell, A. E., and Calvin, M. 1952. Chemistry of the metal chelate compounds, LWW.

Mellor, D., and Dwyer, F. 1964. Chelating agents and metal chelates, Academic Press.

Misra, M., Athar, M., Hasan, S. K., et al. 1988. Alleviation of nickel-induced biochemical alterations by chelating agents. Fundamental and Applied Toxicology 11 (2): 285292. http://dx.doi.org/10.1016/0272-0590(88)90153-4.

Motekaitis, R. J., Cox Iii, X., Taylor, P., et al. 1982. Thermal degradation of EDTA chelates in aqueous solution. Canadian Journal of Chemistry $\mathbf{6 0}$ (10): 1,207-1,213. http://dx.doi.org/10.1139/v82-179.

Nasr-El-Din, H. A., Al-Ghamdi, A. H., Al-Qahtani, A. A., et al. 2008. Impact of Acid Additives on the Rheological Properties of a Viscoelastic Surfactant and Their Influence on Field Application. SPE J. 13 (1): 35-47. SPE-89418-PA. http://dx.doi.org/10.2118/89418-PA.

Nasr-El-Din, H. A., Al-Habib, N. S., Al-Mumen, A. A., et al. 2006a. A New Effective Stimulation Treatment for Long Horizontal Wells Drilled in Carbonate Reservoirs. SPE Prod \& Oper 21 (3): 330-338. SPE-56516-PA. http://dx.doi.org/10.2118/56516-PA.

Nasr-El-Din, H. A., and Al-Humaidan, A. Y. 2001. Iron Sulfide Scale: Formation, Removal, and Mitigation. SPE International Symposium on Oilfield Scale, Aberdeen, UK, 30-31 January. SPE-68315-MS. http://dx.doi.org/10.2118/68315$\underline{\mathrm{MS}}$. 
Nasr-El-Din, H. A., and Samuel, M. 2007. Lessons Learned from Using Viscoelastic Surfactants in Well Stimulation. SPE Prod \& Oper 22 (1): 112-120. SPE-90383PA. http://dx.doi.org/10.2118/90383-PA.

Nasr-El-Din, H. A., Taylor, K. C., and Al-Hajji, H. H. 2002. Propagation of Cross-linkers Used in In- Situ Gelled Acids in Carbonate Reservoirs. SPE/DOE Improved Oil Recovery Symposium, Tulsa, USA, 13-17 April. SPE-75257-MS. http://dx.doi.org/10.2118/75257-MS.

Nelson, E. B., Lungwitz, B., Dismuke, K., et al., 2005. Viscosity Reduction of Viscoelastic Based Fluids. US Patent No. 6881709 B2.

Oviedo, C., and Rodríguez, J. 2003. EDTA: the chelating agent under environmental scrutiny. Quimica Nova 26 (6): 901-905. http://dx.doi.org/10.1590/S0100$\underline{40422003000600020 .}$.

Putnis, A., Putnis, C. V., and Paul, J. M. 1995. The Efficiency of a DTPA-Based Solvent in the Dissolution of Barium Sulfate Scale Deposits. SPE International Symposium on Oilfield Chemistry, San Antonio, Texas, USA, 14-17 February. SPE-29094MS. http://dx.doi.org/10.2118/29094-MS.

Renouf, P., Mioskowski, C., Lebeau, L., et al. 1998. Dimeric surfactants: first synthesis of an asymmetrical gemini compound. Tetrahedron Letters 39 (11): 1357-1360. http://dx.doi.org/10.1016/S0040-4039(97)10835-8.

Samuel, M., Marcinew, R., Al-Harbi, M., et al. 2003. A New Solids-Free Non-Damaging High Temperature Lost-Circulation Pill: Development and First Field Applications. SPE Middle East Oil Show, Bahrain, 9-12 June. SPE-81494-MS. http://dx.doi.org/10.2118/81494-MS.

Saxon, A., Chariag, B., and Abdel Rahman, M. R. 2000. An Effective Matrix Diversion Technique for Carbonate Reservoirs. SPE Drill \& Compl 15 (1): 57-62. SPE62173-PA. http://dx.doi.org/10.2118/62173-PA.

Schramm, L. L., Stasiuk, E. N., and Marangoni, D. G. 2003. 2 Surfactants and their applications. Annual Reports Section "C"(Physical Chemistry) 99 3-48. http://dx.doi.org/10.1039/B208499F.

Shu, Y., Wang, G., Nasr-El-Din, H. A., et al. 2016. Interactions of Fe (III) and Viscoelastic- Surfactant-Based Acids. SPE Prod \& Oper 31 (1): 29-46. SPE165149-PA. http://dx.doi.org/10.2118/165149-PA. 
Sullivan, P., Nelson, E. B., Anderson, V., et al. 2007. "Oilfield applications of giant micelles." In Giant Micelles Properties and Application, edited by E. W. Kaler and R. Zana, 453-472. CRC Press.

Sýkora, V. r., Pitter, P., Bittnerová, I., et al. 2001. Biodegradability of ethylenediaminebased complexing agents. Water research 35 (8): 2010-2016. http://dx.doi.org/10.1016/S0043-1354(00)00455-3.

Taylor, K. C., and Nasr-El-Din, H. A. 2002. Coreflood Evaluation of In-Situ Gelled Acid . SPE International Symposium and Exhibition on Formation Damage Control, Lafayette, Louisiana, 20-21 February. SPE-73707-MS. http://dx.doi.org/10.2118/73707-MS.

Taylor, K. C., and Nasr-El-Din, H. A. 2003. Laboratory Evaluation of in situ Gelled Acids for Carbonate Reservoirs. SPE J. 8 (4): 426-434. SPE-87331-PA. http://dx.doi.org/10.2118/87331-PA.

Thomas, R. L., Ali, S. A., Robert, J. A., et al. 1998. Field Validation of a Foam Diversion Model: A Matrix Stimulation Case Study. SPE Formation Damage Control Symposium, Lafayette, Louisiana, USA, 18-19 February. SPE-39422-MS. http://dx.doi.org/10.2118/39422-MS.

Walker, M. L., Dill, W. R., Besler, M. R., et al. 1991. Iron Control in West Texas SourGas Wells Provides Sustained Production Increases. J Pet Technol 43 (5): 603607. SPE-20122-PA. http://dx.doi.org/10.2118/20122-PA.

Yang, J., Cui, W., Lu, Y., et al. 2015. Instant gel formation of viscoelastic surfactant fracturing fluids by diluting through lamellar liquid crystal. J. Pet. Sci. Eng. 125 (1): 90-94. http://dx.doi.org/10.1016/j.petrol.2014.11.023.

Yeager, V., and Shuchart, C. 1997. In Situ Gels Improve Formation Acidizing. Oil \& Gas J 95 (3): 70-72. 


\section{APPENDIX A \\ DETAILS OF EXPERIMENTAL METHOD}

\section{HP/HT Viscometer (Grace M5600)}

Instrument Calibration

The viscometer (shown in Fig. A.1) can be used to measure the viscosity and dynamic studies of non-Newtonian fluid at high temperature and high pressure. The measurement range is shown below:

Shear rate: $0.00004 \sim 1870 \mathrm{~s}^{-1}$

Speed range: $0.0001 \sim 1100 \mathrm{rpm}$ continuous

Amplitude range: $0.1 \% \sim 500 \%$ (with dynamic option)

Frequency range: $0.01 \sim 5 \mathrm{~Hz}$ (with dynamic option)

Temperature range: ambient $\left(20^{\circ} \mathrm{F}\right.$ with chiller $) \sim 500^{\circ} \mathrm{F}$

Pressure range: atm 1000 psi

Sample size: $32 \sim 78 \mathrm{ml}$

Viscosity range: $0.5 \sim 5,000,000 \mathrm{cp}$

Shear stress: $1 \sim 15,000$ dyne $/ \mathrm{cm}^{2}$

Torque: 14 mN.m 100 mN.m

Repeatability: $\pm 0.5 \%$ of full scale range or better

Resolution: $0.01 \%$ of full scale range or better 


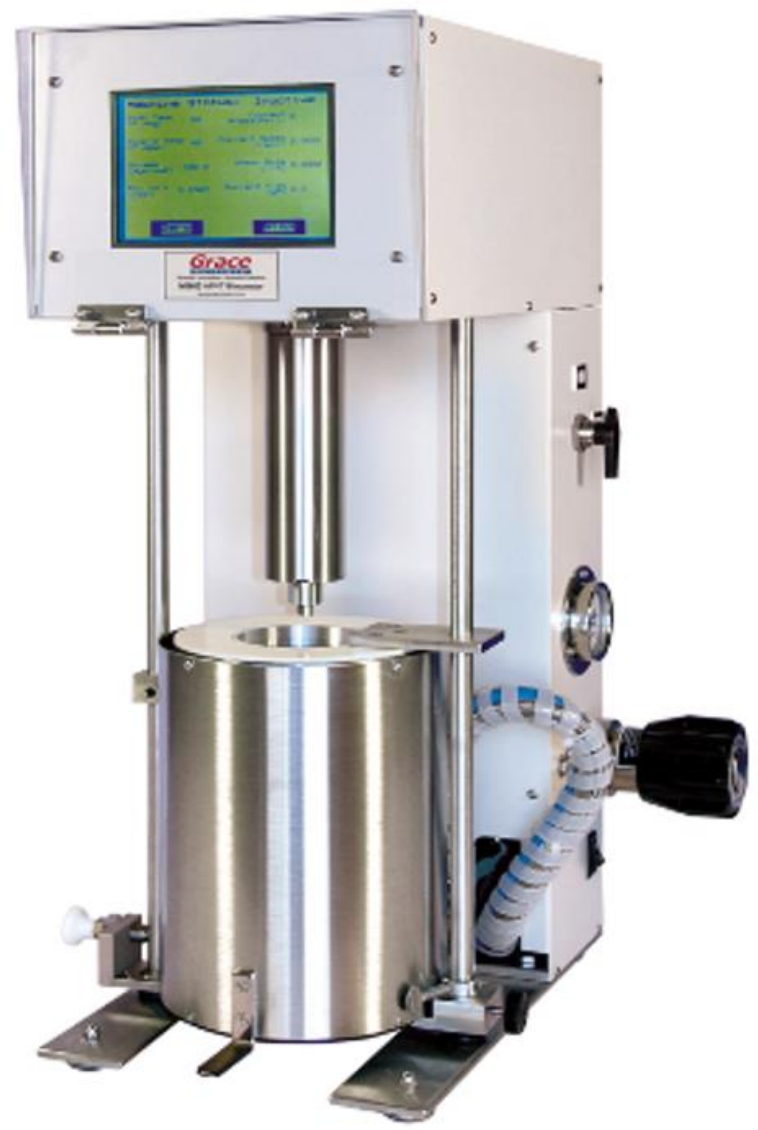

Fig. A.1. HP/HT viscometer (Grace M5600).

\section{Pressure Calibration}

First of all Click on the "Pressure Effect Calibration" tab (shown in Fig. A.2) and then click "Start Automatic Pressure Effect Calibration". Then follow the directions on the lower part of the screen. Finally, Once the pressure calibration is complete, the shear stress reading on M5600 LCD screen should be $\pm 5 \mathrm{dyne} / \mathrm{cm}^{2}$ based on the value from the torque calibration. 


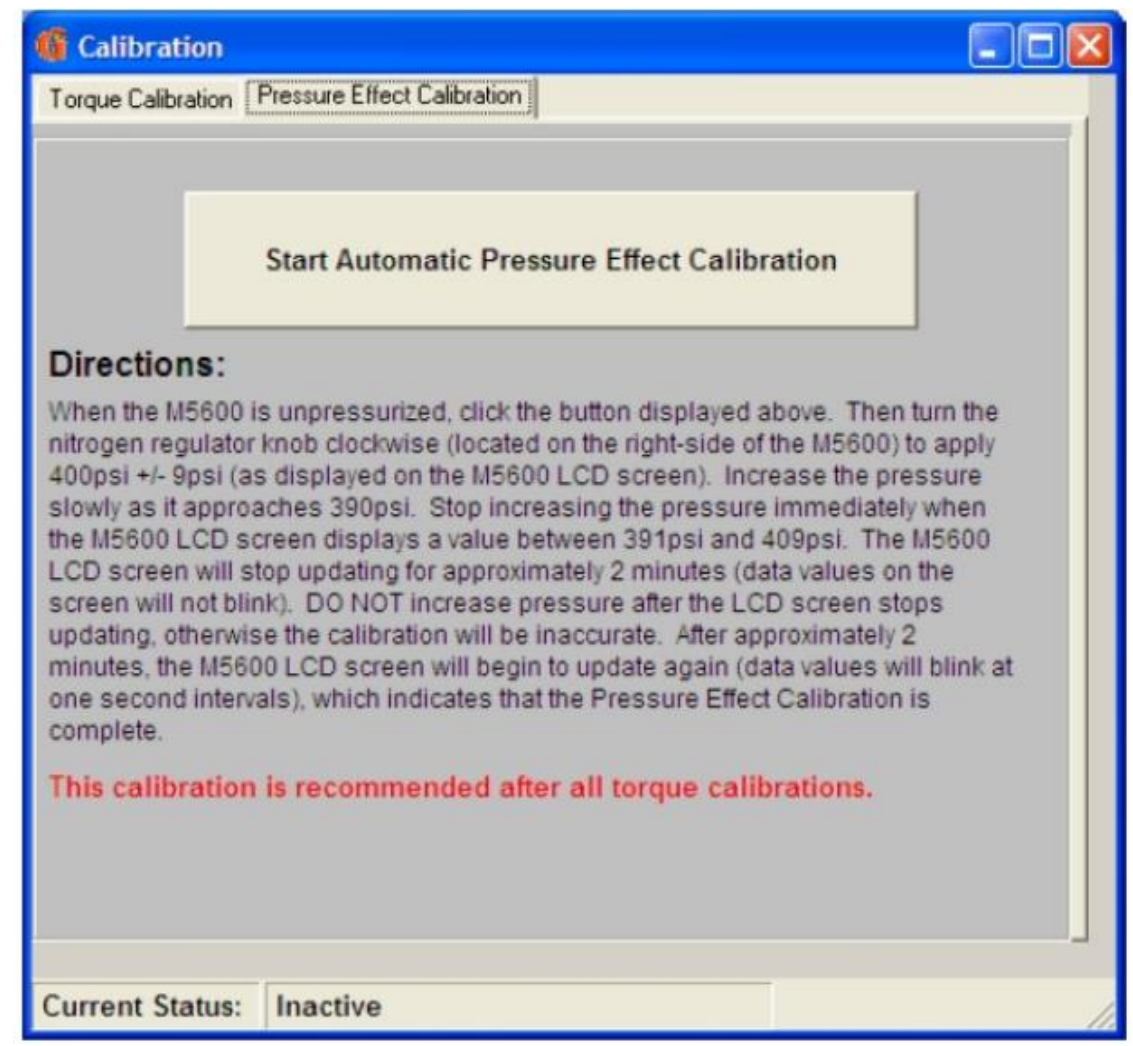

Fig. A.2. Pressure calibration screen.

\section{Torque Calibration}

1) Display the Calibration screen (Fig. A.3.). 2) Select the rheometer and bob size.

3) Enter the viscosity rating for the calibration fluid by matching the viscosity value with the sample temperature displayed on the M5600 LCD screen. The calibration fluid must be loaded into the sample cup before the reading can be taken. 4) Enter the parameter for how much the viscosity 146 of calibration fluid is affected by an increase in temperature of $1^{\circ} \mathrm{C}$. 5) Begin the torque calibration. 6) After the torque calibration, wait for a few minutes, then check the shear stress reading on the M5600 LCD screen. It should be in the 
range of $-10 \sim 10 \mathrm{dyne} / \mathrm{cm}^{2}$. If the reading is outside of this range, the head assembly needs cleaning.

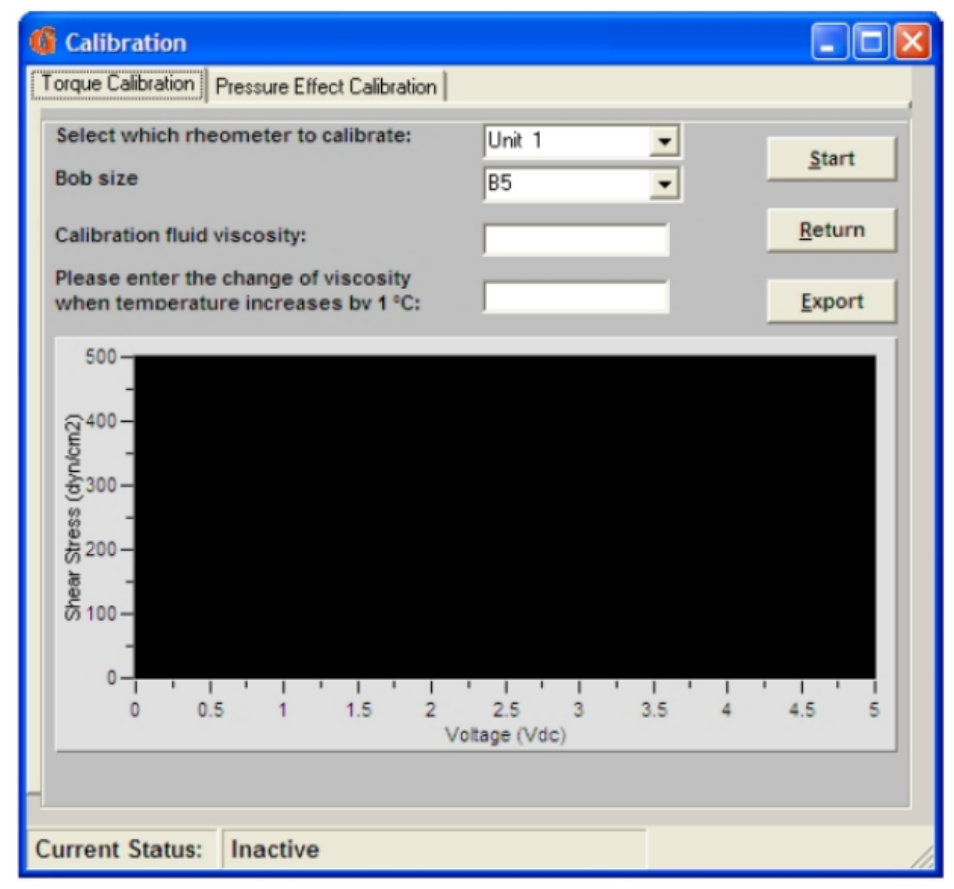

Fig. A.3. Torque calibration screen.

\section{Oscillatory Test Procedure}

Real time oscillatory tests are divided into two types: single step and pre-saved sequence.

\section{A Single Step Real Time Oscillatory Test}

First Click "Oscillatory Test" in the menu bar and choose "Add M5600 Unit 1". The screen is shown in Fig. A.4. Install the proper bob, click "Zero" button, then install the sample cup, loaded with fluid. Enter the appropriate values for the test, including bob size, 
chart type, strain (\%), frequency/Hz, delay cycles and number of cycles to average. Finally click the "Start" button.

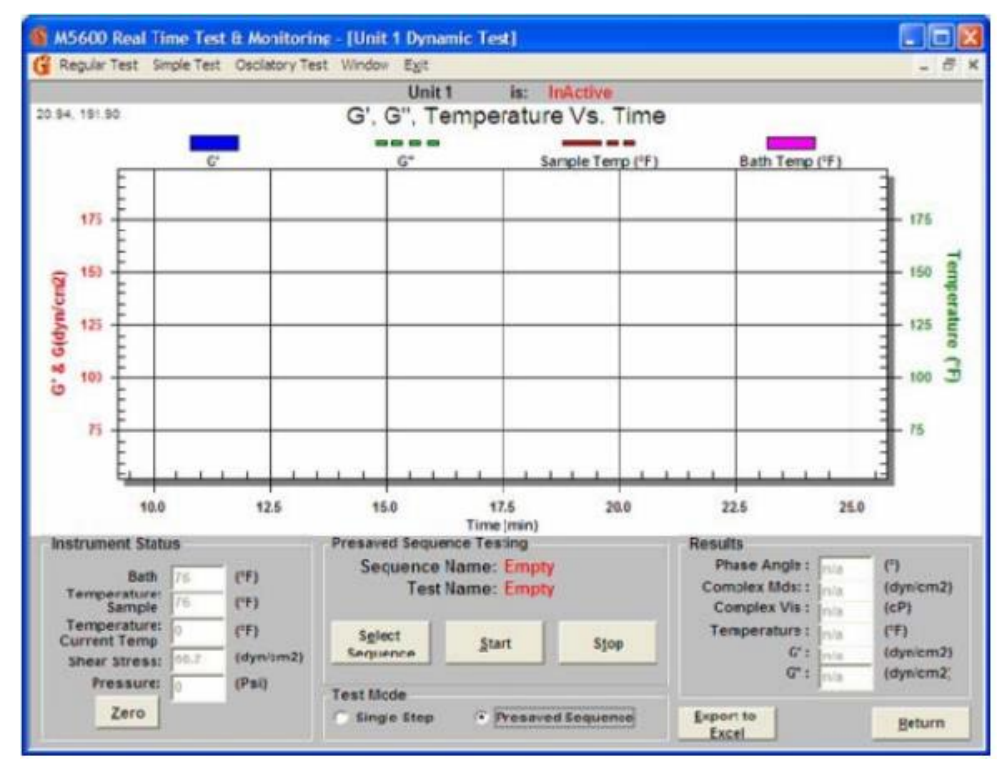

Fig. A.4. Single step real time oscillatory.

\section{Pre-saved Sequence Real Time Oscillatory Test}

First Click "Oscillatory Test" in the menu bar and choose "Add M5600 Unit 1". Click "Pre-saved Sequence". (Fig. A.5). Then Click "Select Sequence" to choose a presaved test sequence. Install the proper bob, click "Zero" button, then install the sample cup, loaded with fluid. Click "Start" to bring up the test window. Enter a unique name for the test file, and click "OK" to start the test. 


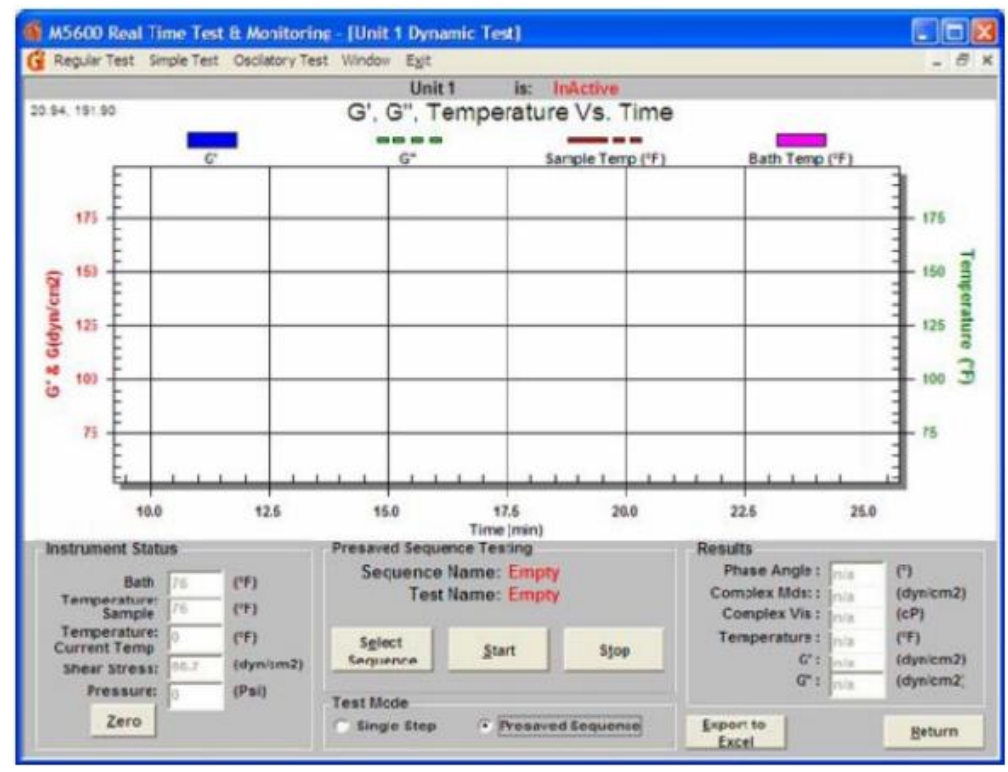

Fig. A.5. Pre-saved sequence real time oscillatory test screen.

\section{Viscometry Test Procedure}

1) Click "Setup" tap on the main screen and test sequence setup will appear (Fig. A.6). 2) Choose "Viscometry, API 39" test type.

2) Create the sequence steps. Choose "temperature", "shear rate" and "ramp".

3) Save the sequence and click "return" button.

4) Click the "Real Time Test" button on the main screen. And then click "Regular Test" in the menu bar and choose "Add M5600 Unit 1". The screen is shown in Fig. A.6.

5) Load the sample cup with a homogenous sample.

6) Click the "Zero" button to establish a zero value for the torque sensor.

7) Install the sample cup, loaded with the sample and turn the nitrogen pressure regulator knob clockwise to set the desired pressure. 
8) Raise and secure the bath.

9) Click on the "Select Sequence" button to display pre-saved test files. Then click on the desired sequence.

10) Click "Start". The test information will show up and "Test Name" is the only mandatory field.

11) Click "OK" to start the test.

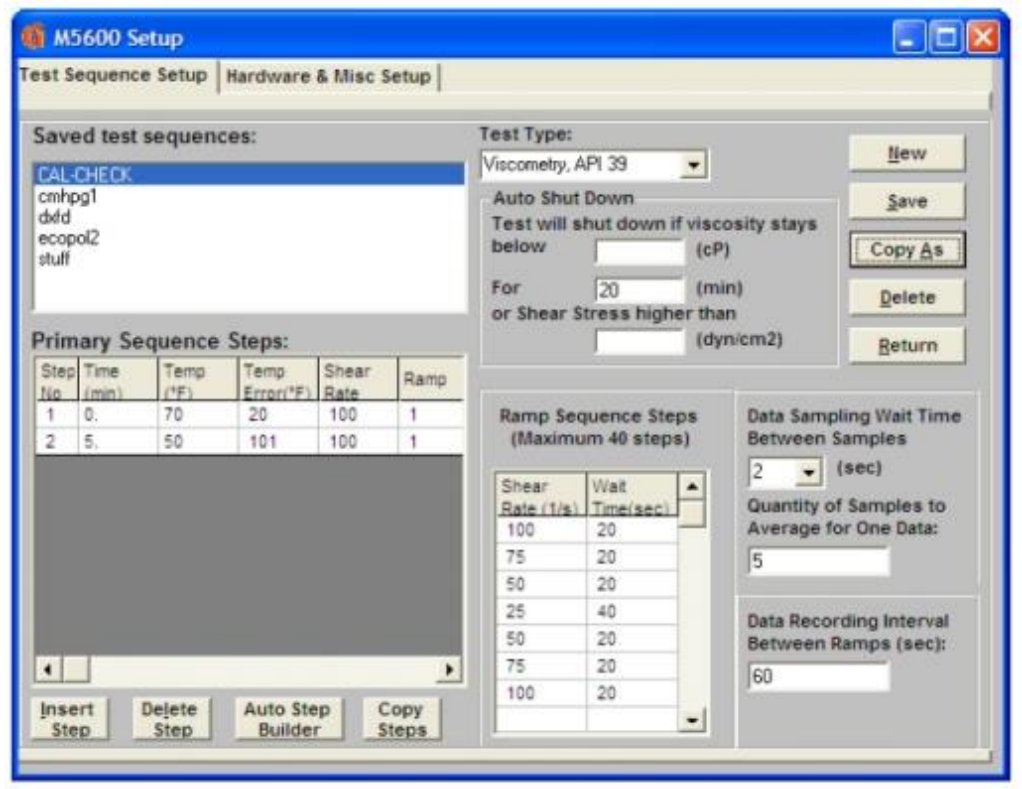

Fig. A.6. Test sequence setup screen. 


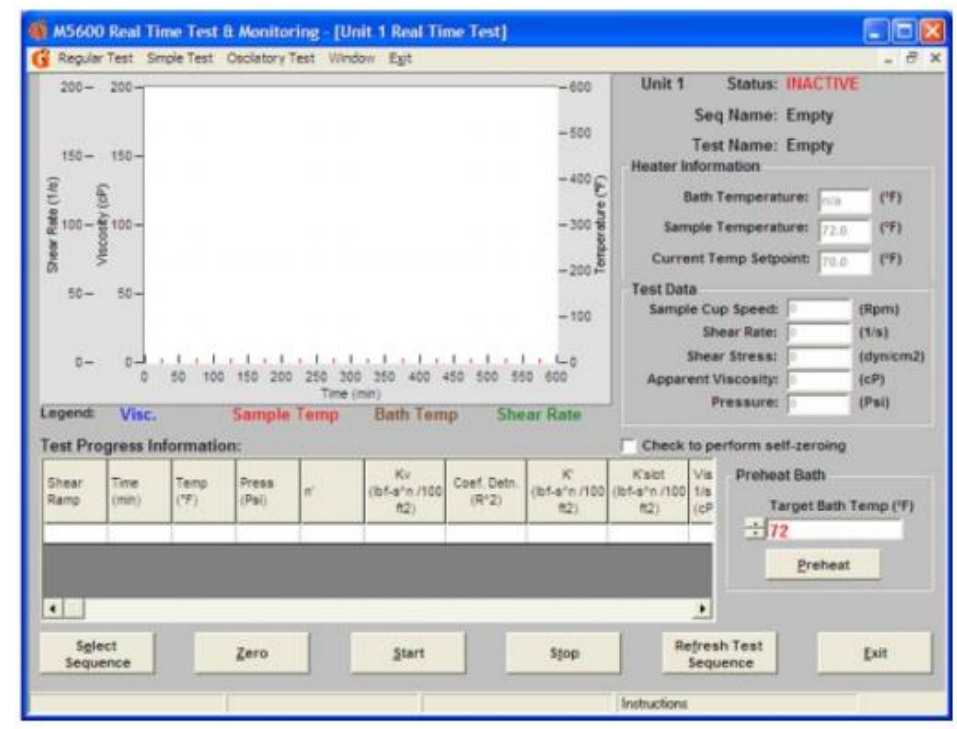

Fig. A.7. Real time test screen. 